\title{
用火山岩制约南海的形成演化: 初步认识与研究设想
}

\author{
徐义刚 ${ }^{(1)}$, 魏静娴 ${ }^{(12)}$ ，邱华宁 ${ }^{(1)}$ ，张辉煌 ${ }^{(1)}$ ，黄小龙 ${ }^{(1)}$ \\ (1) 中国科学院广州地球化学研究所, 同位素地球化学国家重点实验室, 广州 510640; \\ (2) 中国科学院研究生院, 北京 100049 \\ E-mail: yigangxu@gig.ac.cn
}

2011-07-27 收稿, 2011-11-15 接受

国家自然科学基金重大研究计划(91128203)、国家重点基础研究发展计划(2011CB808906)和中国科学院海外团队项目资助

\begin{abstract}
摘要 同其他边缘海相比, 南海海山众多, 且分布广泛, 记录了南海演化以及相关深部过程的 重要信息. 南海及邻区的火山作用可分成 3 期：南海张开之前(pre-spreading, >32 Ma), 张开期 间 (syn-spreading, 32 16 Ma)和张开期后 (post-spreading, <16 Ma). 南海张开之前的岩浆活动 (64 35 Ma)主要局限在南海北缘和华南沿海一带, 以双峰式火山岩为基本特征. 南海扩张期岩 浆活动在南海周边的分布非常少见, 而主要分布于南海海盆, 但由于海盆中沉积物非常厚, 至 今未获得该期岩浆的样品. 南海扩张期后的岩浆活动广泛分布于中央海盆、西南次海盆、海南 岛、雷州半岛、泰国、越南等地, 以碱性玄武岩为主, 少数为拉斑玄武岩, 具有 OIB 地球化学 特征, 源于 DM-EM2 之间的混合地幔源, 显示 DUPAL 同位素异常; 火山岩中橄榄石斑晶的 Fo 含量达 $90.7 \%$, 表明火山岩可能是海南地幔柱活动的产物. 南海及邻区新生代火山岩的时空分 布可能与南海扩张过程中洋中脊对地幔柱的抽吸作用(ridge suction)有关, 如是, 南海海盆火山 岩可能不是典型的 MORB. 但令人费解的是, 华南大陆边缘-南海海盆的过渡带不具备火山裂 解边缘(volcanic rifted margin)的特点. 显然, 地幔柱活动与南海张开之间的关系尚需进一步的 研究. 在南海重大研究计划的实施过程中, 只有有效规划和组织海底火山岩样品的采集, 并加 强火山岩成因和深部动力学研究的联系, 才能阐明深部过程与南海张裂演化之间的联系.
\end{abstract}

关键词

火山作用

地幔熔融

华南大陆边缘

裂解

南海扩张

海南地幔柱
国家自然科学基金“南海深海过程演变”重大研 究计划拟解决的关键科学问题之一是南海的形成与 演化, 即南海海盆扩张的起始和终止时间及动力学 控制因素. 目前就此问题还存在较大的分歧. 南海洋 盆扩张的构造复原主要依据海底磁异常条带, 主流的 看法是南海扩张开始于 $32 \mathrm{Ma}$, 停止于 $15.5 \mathrm{Ma}^{[1 \sim 3]}$, 但 $\mathrm{Hsu}$ 等人 ${ }^{[4]}$ 认为南海早在 $37 \mathrm{Ma}$ 之前就已经打开. 南海海盆包括西南次海盆、中央海盆和东部次海盆, 这些海盆在时空上的扩张形式是否存在不均一性, 是否与区域构造事件相匹配? 是否形成了洋壳? 此 外, 近年来地球物理探测揭示海南岛附近下方地幔 存在低速结构, 从浅部向下穿越 $660 \mathrm{~km}$ 的不连续面 处(上下地幔的分界面)并一直延伸到 $1900 \mathrm{~km}^{[5 \sim 7]}$, 被
称为“海南地幔柱”, 其影响范围主要通过地表出露 的新生代碱性岩为依据, 包括南海、雷州半岛以及中 南半岛等地区，影响范围达 $4 \times 10^{6} \mathrm{~km}^{2}$ 以上(图 1) ${ }^{[8]}$. 如果海南地幔柱的确存在, 那么地幔柱活动是否导 致了南海的张开? 在南海广泛发育的呈线状分布的 火山链是否是海南地幔柱活动的产物?

对洋壳和火山链样品的年龄测定和成分分析, 可以对南海海盆的形成时限和深部活动提供约束. 根据大洋玄武岩的研究成果可以推测, 南海海盆中可 能产出两种类型的玄武岩, 即洋中脊玄武岩 $(\mathrm{MORB})$ 或洋岛玄武岩 $(\mathrm{OIB})$. 当然, 在洋中脊-地幔柱相互作 用的情形下，还可产出性质介于两者之间的岩浆 ${ }^{[13]}$ MORB 代表了大洋洋壳的样品, 如果能了解其时空

英文版见: Xu Y G, Wei J X, Qiu H N, et al. Opening and evolution of the South China Sea constrained by studies on volcanic rocks: Preliminary results and a research design. Chin Sci Bull, 2012, 57, doi: 10.1007/s11434-011-4921-1 


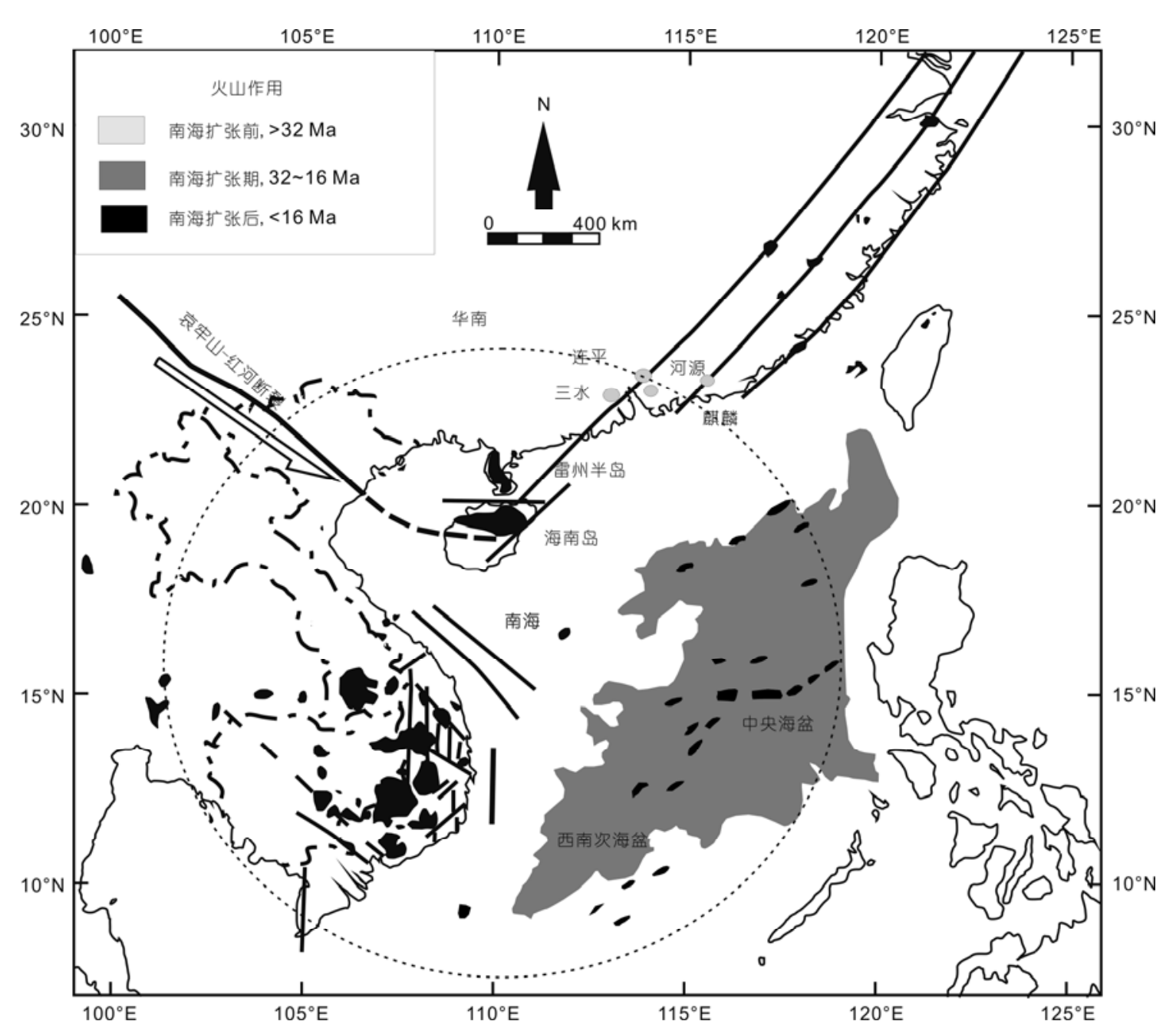

图 1 南海及邻区新生代火山岩分布简图

据文献[9 12]综合修改. 南海扩张期岩浆的分布根据磁异常推测 ${ }^{[1,11]}$. 虚线圆圈为推测的海南地幔柱影响的范围 ${ }^{[8]}$

分布特征, 就可直接制约洋盆的形成时代和扩张的 形式及速率. OIB 则是深部对流地幔部分熔融的产物, 其形成过程及化学组成受控于地幔源区特征、部分熔 融程度、地幔潜能温度和岩石圈厚度等多个因素. 如 能区分这些因素对玄武岩组成变化的相对贡献, 那 么玄武岩组成就可用以反演深部地幔/岩石圈的演化 历史 ${ }^{[1421]}$. 事实上，同其他边缘海相比，南海海山众 多, 且分布广泛, 为系统地揭示南海形成与演化提供 了不可多得的地质条件.

本文首先简要阐述用火山岩制约岩石圈形成与 演化的基本概念和方法, 然后评述南海及邻区火山 岩的研究现状, 在初步总结这一地区火山岩的岩石 类型及其时空演化特征的基础上，提出从火山岩角 度对南海形成与演化的初步认识. 最后就解决“南海
深海过程演变”重大研究计划中的关键问题提出研究 设想.

\section{1 用火山岩约束岩石圈演化的基本方法}

\section{1 导致地幔部分熔融的方式和产生岩浆的类型}

玄武质岩浆是软流圈地幔经部分熔融形成的。 导致地幔发生熔融的必要条件是绝热地温线与地幔 固相线相交. 在正常情况下, 大洋和大陆地温线都不 与干橄榄岩固相线相交(图2(a)). 促使两者相交有 3 种 方式 ${ }^{[19]}$ : (1) 地幔热柱使得地温线升高(图 2(b)), 形成 OIB 型岩浆及大火山岩省; (2) 岩石圈拉张使得软流 圈绝热上涌的减压熔融(图 2(c)), 如形成大洋中脊玄 武岩(MORB); (3) 挥发分的加人导致固相线降低, 例 


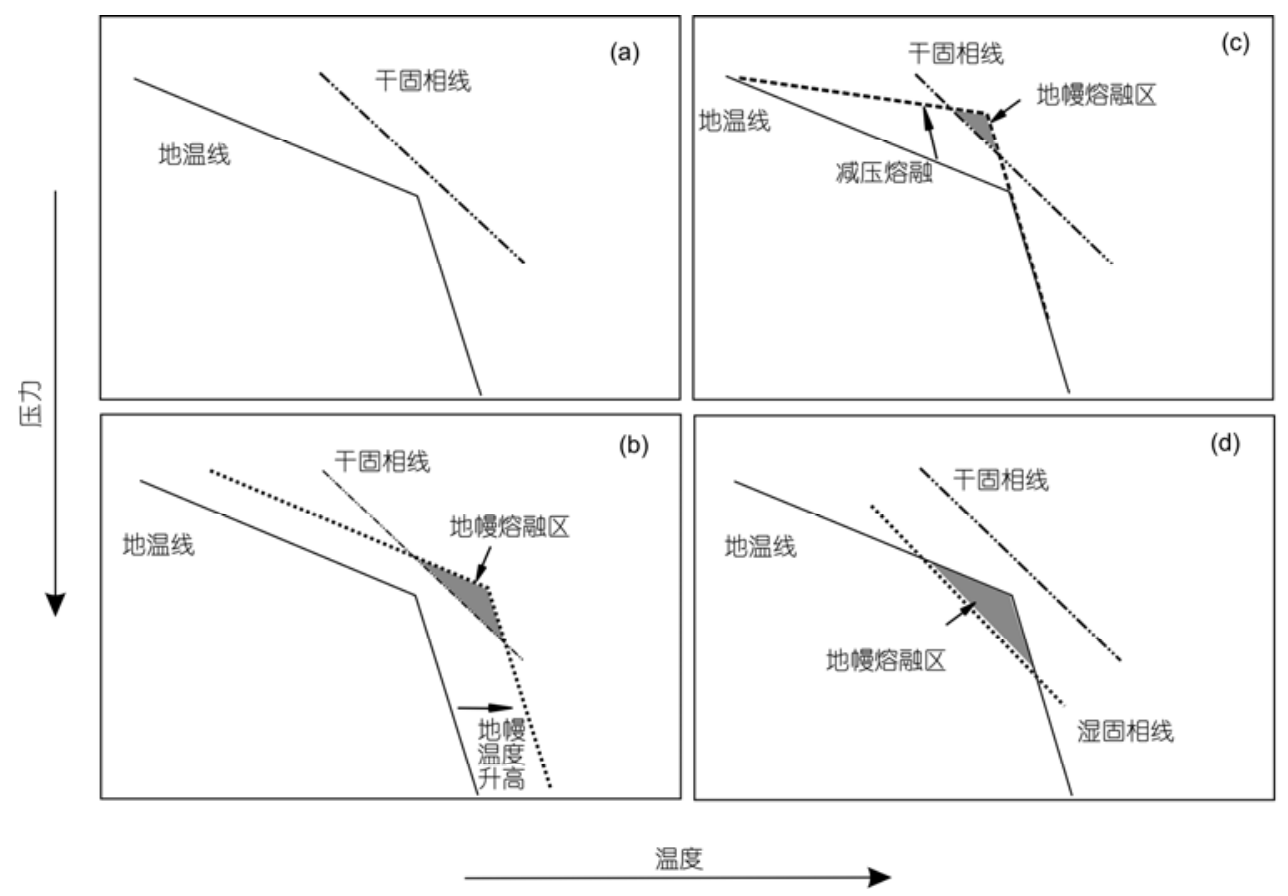

图 2 地幔发生熔融的 3 种方式

据文献[19]修编. (a) 正常情况下, 地温线不与固相线相交, 不发生熔融; (b) 地幔温度升高, 导致地温线与固相线相交而发生部分熔融; (c) 拉 张过程中地幔绝热减压上升引起部分熔融; (d) 挥发分加入降低固相线而引发部分熔融

如汇聚板块边界的地幔楔熔融(图 2(d)). 南海的演化 过程可能与岩石圈的拉张或与地幔柱活动的叠加有 关, 因此南海及其邻区的新生代火山岩最有可能的 类型是 MORB 和 OIB. 当然, 南海是弧后扩张中心的 可能性还不能完全排除.

\section{2 用火山岩制约岩石圈演化的方法}

研究表明, 玄武岩浆的形成与地幔多压、分异熔 融(而非平衡熔融)有关. 在地表观察到的玄武岩不是 地幔某一深度熔融的产物, 而是不同深度产出的不 同熔融程度熔融体的混合物 ${ }^{[16,19]}$. 简单地说, 软流圈 地幔的熔融行为可以用熔融柱(melting column)模型 来描述 ${ }^{[16]}$. 当绝热上升的软流圈温度超过固相线时, 软流卷地幔进入熔融区, 开始熔融的压力称之为初始 压力 $P_{\mathrm{o}}$ (initial pressure). 随着软流圈不断地上升、压 力不断减小、熔融程度也不断增大, 熔体的黏稠度降 低, 最终熔体脱离熔融体系, 这时的压力称之为最终 压力 $P_{\mathrm{f}}$ (final pressure) ${ }^{[14]}$. 可见这些聚集的熔体来源 于一定的深度范围(图 3(a), (b)), 熔融柱的长度反映 出熔体所经历的压力范围和熔融程度. 如果岩浆源 区成分相对均一, 那么岩浆成分主要取决于地幔温
度和特定地区的岩石圈厚度这两大主要因素 ${ }^{[15,19]}$ 这两个参数可以转化为熔融柱中的地幔起始熔融深 度和终止熔融深度. 起始熔融深度与地幔温度有关, 温度越高, 起始熔融深度就越大 (图 3(c), (d)). 终止 熔融深度则受岩石圈厚度所控制 ${ }^{[15,18]}$, 刚性岩石圈 象“盖”一样阻止软流圈的进一步上涌, 所以厚岩石 圈下地幔熔融的深度要大于薄岩石圈下的地幔熔融 深度(图 3). 玄武质岩浆形成的最终深度(即熔融柱顶 端)受岩石圈厚度的这种控制作用称作岩石圈盖效应 (Lithospheric lid effect $)^{[15,21,22]}$. 根据这个模型, 如果 能知道玄武岩的最终深度, 就可以推算出其上覆岩 石圈的厚度.

洋中脊玄武岩和与地幔柱活动有关的溢流玄武 岩提供了地幔熔融的两种极端情况(图 3(c), (d)). 在 洋中脊, 由于地幔温度低 $\left(T \mathrm{p} \sim 1300^{\circ} \mathrm{C}\right)$, 地温线与地 幔固相线在较浅部位才相交(图 3(c)), 因而地幔起始 熔融深度小 $(80 \mathrm{~km})^{[23]}$, 但由于岩石圈薄, 地幔减压 熔融作用可一直延续到很浅部位, 较长的熔融区间 (melting interval)保证了较大的部分熔融程度, 洋中 脊玄武岩 (MORB) 因而通常反映尖晶石“指纹”(即 REE 含量低, 且 HREE 分异不明显). 相反，地幔热柱 


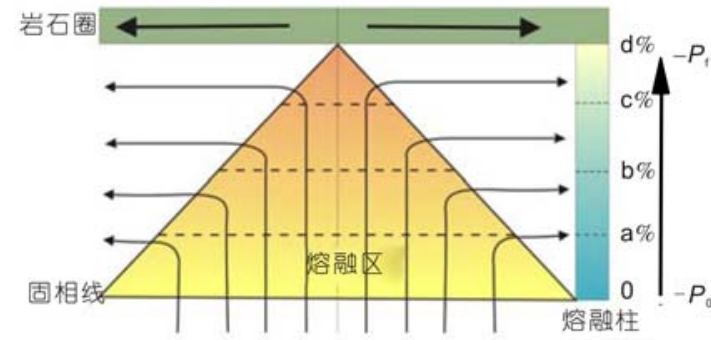

(a)

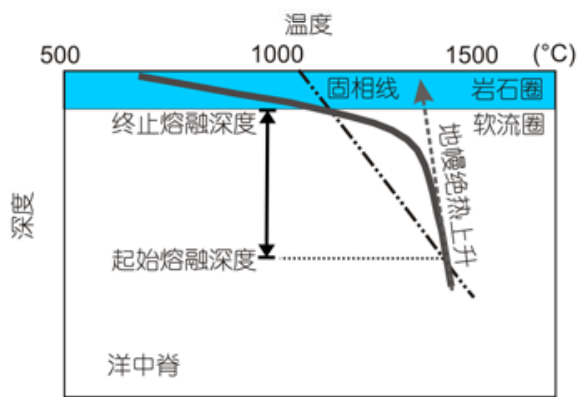

(c)

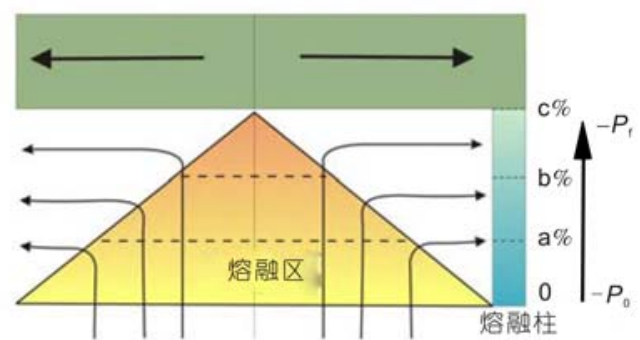

(b)

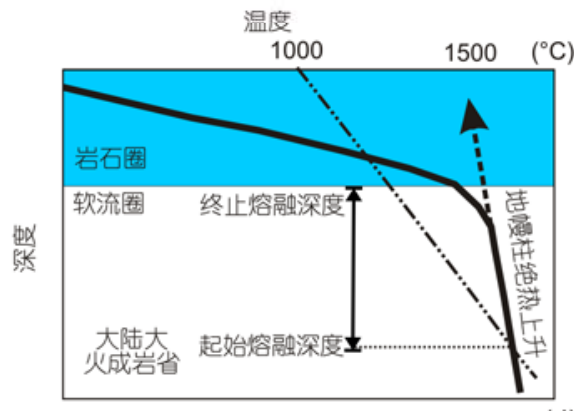

(d)

图 3 地幔熔融柱模型((a), (b))和岩石圈盖效应示意图((c), (d))

据文献 $[16,19]$ 综合修改. ((a), (b)) 描述了当地幔潜能温度相同, 但岩石圈厚度不同的地幔熔融情形. $P_{\mathrm{o}}$, 地幔进入熔融区的初始压力; $P_{\mathrm{f}}$, 熔体脱 离熔融区的最终压力; 带箭头细线表示地幔流, 箭头所指熔融柱值表示熔体的熔融程度; 当地幔流进人熔融区的初始压力 $P_{\mathrm{o}}$ 相同时, 岩石圈 的加厚使得熔体的最终压力 $P_{\mathrm{f}}$ 增大, 熔融区变小也意味着整体熔体体积的减少且平均熔融程度减小. 图中箭头长度代表了地幔减压熔融区间 范围. ((c), (d))描述地幔潜能温度和岩石圈厚度均不同时的情形, 其中, (c)和(d)分别对应于洋中脊和大陆大火成岩省的地幔熔融

温度高 $\left(T \mathrm{p} \sim 1500^{\circ} \mathrm{C}\right)$, 地温线与地幔固相线在很深位 置(石榴石稳定区) 就相交(图 3(d)), 即地幔开始熔融 的深度大 $(>120 \mathrm{~km})$. 但由于上覆岩石圈厚度大, 地 幔减压熔融因而被阻止于较深位置, 导致地幔熔融 区间较短(局限于石榴石稳定区), 部分熔融程度较低, 从而形成分异程度较高的 REE 分布模式. 这导致大 火成岩省岩浆的部分熔融程度低于 MORB, 而且常 常显示石榴石“指纹”. Humphreys 和 $\mathrm{Niu}^{[20]}$ 及 $\mathrm{Niu}$ 等 人 $^{[21]}$ 的工作证明全球 OIB 的地球化学成分受控于大 洋岩石圈的厚度.

由此可见, 只要能够限定不同时代玄武岩的起 始和终止熔融深度, 就可以获得有关深部演化(地幔 温度和岩石圈)的信息. 有 4 种方法可定性或定量地 确定岩浆生成时的岩石圈厚度.

(1) 同位素反演: 独立于对流软流圈的岩石圈地 幔因同位素衰变而形成与软流圈地幔截然不同的同 位素组成 ${ }^{[24,25]}$. DePaolo 和 Daley ${ }^{[26]}$ 发现美国西南部 晚新生代玄武岩同位素特征变化与岩石圈减薄程度 相关, 即在岩石圈减薄前或减薄初期, 岩石圈是玄武 岩浆的主要源区, 随着减薄程度不断地增大, 软流圈
逐渐成为玄武岩浆的源区. 这意味着随时间演化的 玄武岩同位素特征变化可以揭示岩石圈厚度变化过 程. 在无地幔柱存在的区域, 在岩石圈拉张早期(拉 张系数 $\beta<1.2)$, 岩石圈地幔会首先发生熔融, 不过少 量的挥发分并不会引起岩石圈地幔的大规模熔融 ${ }^{[19]}$, 软流圈仍然是上地幔的主要熔融区 ${ }^{[23,27]}$. 在拉张过 程中，当岩石圈富含的挥发组分消耗完时，岩石圈厚 度仍大于 $100 \mathrm{~km}$, 由于软流圈熔融条件是在岩石圈 厚度小于 $80 \mathrm{~km}^{[23]}$, 这暗示在岩石圈减薄过程中, 从岩石圈熔融转变到软流圈熔融具有短暂的岩浆间 歇期 ${ }^{[19]}$. 需要指出的是, 这种方法只能定性地判断 岩石圈的减薄过程, 而无法定量地描述岩石圈厚度 的变化.

（2）岩性反演：玄武岩的岩性不仅受到源岩成分 的控制, 还受到温度、压力以及熔融程度的控制 ${ }^{[28,29]}$. 类似原始地幔成分的橄榄岩 (pyrolite)的无水熔融实 验表明, 与拉斑质岩浆相比, 碱性玄武岩或更不饱和 的岩浆形成深度应大于 $10 \mathrm{kbar}\left(1 \mathrm{bar}=10^{3} \mathrm{hPa}\right.$, 下同)且 所需熔融程度小于 $15 \%$; 对橄榄岩(PHN1611)熔融实 验也得出相似的结论 ${ }^{[29,30]}$, 即在低压条件下 $(<10 \mathrm{kbar})$, 
经大程度熔融生成具有紫苏辉石和石英标准矿物的 拉斑玄武岩; 当压力 $>12$ 15 kbar 时, 生成碱性玄武 岩(霞石标准矿物 $\mathrm{Ne}<10 \%$ ); 而当压力 $>25 \mathrm{kbar}$ 时, 则生成霞石岩和黄长岩 $(\mathrm{Ne}>10 \%)$ 且熔融程度 $<10 \%$, 由此可知, 通过玄武岩岩性可以来初步判断玄武岩 的形成深度, 但仍无法定量计算玄武岩的形成深度.

(3) 稀土元素反演: 由于稀土元素 (REE)的分配 系数在尖晶石和石榴石之间具有非常显著的差异 ${ }^{[31]}$, 因此 REE 成为拉张因子 $(\beta)$ 的敏感指示. 上地幔尖晶 石-石榴石转换带位于 $60 \sim 80 \mathrm{~km}$ 深度 ${ }^{[32,33]}$, 当 $\beta$ 大约 为 $1.5 \sim 2$ 时, 会使熔融柱顶部位于这一区域; 当 $\beta<1.5$ 时, 残留的石榴石会越来越重要, 熔体会显示出强烈 残留石榴石特征(高 $\mathrm{Sm} / \mathrm{Yb}$ ) ${ }^{[15]}$; 当 $\beta>2$ 时, 熔体表现 出与尖晶石平衡的 REE 特征(低 $\mathrm{Sm} / \mathrm{Yb}$ ); Ellam $^{[15]}$, Fram 和 Lesher ${ }^{[22]}$ 以及 McKenzie 和 $\mathrm{O}^{\prime} \mathrm{Nions}^{\left[{ }^{[31]}\right.}$ 成功运 用 REE 反演了玄武岩的形成深度. 虽然 REE 能定量 反演玄武岩的深度, 但存在许多不确定因素: (a) REE 所用分配系数都是在静态压力下实验或估算所得, 而玄武岩是经减压、动态熔融形成; 另外微量元素分 配系数也受到是否含有挥发分的影响, 如含有 $\mathrm{CO}_{2}$ 时, HREE 在单斜辉石中的分配系数是无 $\mathrm{CO}_{2}$ 硅酸盐体 系中 5 200 倍 ${ }^{[34]}$; (b) 计算 REE 含量时, 必须假设各 深度(压力)下橄榄岩的矿物相和成分含量或相变的 反应公式, 以及矿物进人熔体的不同比例关系, 这些 参数将很大程度受到人为的影响.

(4) 主量元素反演: 玄武岩的主量元素组成与形 成压力存在一定的联系, 有些元素在熔融过程中的 行为类似不相容元素, 主要受到熔融程度的制约, 例 如 $\mathrm{Na}_{2} \mathrm{O}$ 和 $\mathrm{TiO}_{2}$. 实验显示玄武岩中 $\mathrm{Na}_{2} \mathrm{O}$ 含量与温 度呈负相关关系 ${ }^{[28]}$. 而另一些元素则是压力变化的 敏感指示, 如 $\mathrm{SiO}_{2}$ 和 $\mathrm{FeO}$, 在较高压力下熔融形成的 玄武岩具有高的 $\mathrm{FeO}$ 和低 $\mathrm{SiO}_{2}$ 含量 ${ }^{[28]}$; 另一方面, 在压力不变的情况下, 熔融程度对这两个元素含量 影响相对较小. 因此通过主量元素的成分特征, 可以 反演玄武岩的形成深度和熔融程度. 例如, Klein 和 Langmuir ${ }^{[35,36]}$ 发现 MORB $\mathrm{Na}_{2} \mathrm{O}-\mathrm{FeO}$ 局部趋势(local trend)和全球趋势 (global trend), 并提出地幔潜能温 度的变化 $(\Delta T \mathrm{p}=250 \mathrm{~K})$ 是造成 MORB 的全球趋势的原 因. 这暗示有些未受地幔柱影响的洋中脊地幔的温 度高于正常地幔 $250^{\circ} \mathrm{C}$, 这令人难以理解. $\mathrm{Niu}$ 和 $\mathrm{O}^{\prime} \mathrm{Hara}^{[37]}$ 对 Langmuir 研究组关于校正火山岩分异 结晶的方法提出了质疑, 并认为 MORB 的全球趋势
可能与地幔成分的继承性和熔融过程的复合作用有 关. Haase ${ }^{[17]}$ 依据 3 个橄榄岩(KLB-1, PHN1611 和 Tinaquillo)的熔融实验 $\mathrm{SiO}_{2}$ 与压力数据的线性回归, 即 $P(\mathrm{GPa})=23.217 \sim 0.4381 \mathrm{SiO}_{2}(R=0.878)$. 事实上, 太 平洋和大西洋板内原始玄武岩形成深度(平均 $\mathrm{SiO}_{2}$ 含 量推算)与岩石圈年龄 ( $\leqslant 70 \mathrm{Ma})$ 成正相关关系.

根据橄榄岩熔融实验, 近年来许多学者都提出 了自己的主量元素熔融模型 ${ }^{[14,16,23,35,38]}$. 其中最为常 用的是 Niu 和 Batiza ${ }^{[14]}$ 的经验模型和 Langmuir 等人 ${ }^{[16]}$ 主量元素动态熔融模型(LKP). LKP 模型有以下特点: (i ) 模型中仅需计算 $\mathrm{MgO}, \mathrm{FeO}, \mathrm{Na}_{2} \mathrm{O}$ 和 $\mathrm{K}_{2} \mathrm{O}$ 含量, 并不需要所有的橄榄岩主量成分; (ii) 在大量实验 数据的基础上建立元素分配系数 $\left(K_{\mathrm{d}}=\mathrm{C}_{\text {mineral }}^{\mathrm{i}} / \mathrm{C}_{\text {melt }}^{\mathrm{i}}\right)$ 与 压力、温度、成分的线性关系, 确保数据的准确性(例 如 $\mathrm{K}_{\mathrm{d}}^{\mathrm{Mg}} \mathrm{O} / \mathrm{Melt}$ 平均误差为 $5.3 \%$ ), 以压力和温度为参数 的 $K_{\mathrm{d}}$ 值可以应用于不同的温压条件; (iii) 模型的前 提条件是在熔融过程中橄榄石总是作为残留矿物(并 不需要将橄榄石作为唯一的残留矿物), 而该条件在 橄榄岩熔融过程中始终成立 ${ }^{[29]}$. Wang 等人 ${ }^{[39]}$ 和张辉 煌等人 ${ }^{[40]}$ 运用 LKP 模型计算了美国盆岭省和中国东 部新生代玄武岩的深度, 所反演的岩石圈厚度与地 球物理所得结果相似. 可见, 虽然 LKP 模型是为研 究 MORB 而建立, 但同样适用于大陆板内玄武岩.

\section{3 用火山岩约束地幔柱活动的方法}

地幔柱的鉴别可从 5 个角度展开 ${ }^{[41,42]}$ : (1) 大规 模火山作用前的地壳抬升; (2) 放射状岩墙群; (3) 火 山作用的物理特征; (4) 火山链的年代学变化或者火 山作用的时限; (5) 产出岩浆的化学组成和下地幔组 成. 考虑到南海为海水覆盖区, 因此(1) (3)的科学目 标是无法实现的. 因此这里重点阐述(4)和(5)这两个 方面. 由地幔柱产生的火山链的年龄应沿板块运动 方向的反方向逐渐变年轻. 在成分上, 由地幔柱活动 形成的火山岩应具有 OIB 特征, 且原始岩浆的成分 应不同于 MORB, 并具有高 $\mathrm{Mg}$ 的特点. 例如, 洋岛 玄武岩 $(\mathrm{OIB})$ 的 $\mathrm{Sr}-\mathrm{Nd}-\mathrm{Pb}$ 同位素组成应落在 DMMHIMU-EM1-EM2 地幔四面体内 ${ }^{[43]}$, 其同位素变化范 围可用这 4 个端员中的某 2 个或某 3 个之间的混合来 解释 ${ }^{[4]}$. 当然, 事物总是十分复杂的, 具有 OIB 特征 的岩浆并不一定就是地幔柱的产物. 例如, 东太平洋 隆起(EPR)附近的玄武岩海山、中国东部新生代玄武 岩均具有 OIB 型的成分特点, 但其成因与地幔柱无 
关 ${ }^{[45 \sim 47]}$. 因此, 对地幔柱的鉴别应从综合的角度，而 非仅仅依赖单一学科.

\section{2 南海及邻区火山岩研究现状}

\section{1 南海及邻区火山岩时空分布特征}

根据海底磁异常条带研究, 推测南海扩张开始 于 $32 \mathrm{Ma}$, 停止于 $15.5 \mathrm{Ma}^{[1 \sim 3]}$. 根据与南海张开事件 (32 15.5 Ma)的前后关系, 将南海及邻区火山作用分 成 3 个阶段(图 4): 即南海海盆张开之前(pre-spreading), 张开期间 (syn-spreading)和张开期后(post-spreading).

(i ) 南海张开之前 $(>32 \mathrm{Ma})$ 的岩浆活动. 该期 岩浆活动主要局限在南海北缘和华南沿海一带(图 1), 如三水、连平和河源盆地的双峰式火山岩(图 4) ${ }^{[9]}$, $\mathrm{K}-\mathrm{Ar}$ 定年结果为 $64 \sim 43 \mathrm{Ma}^{[48]}$, 主要岩性包括玄武 岩、安山岩、英安岩、粗面岩、流纹岩和凝灰岩. 双 峰式岩浆的形成与岩石圈拉张环境中双层对流岩浆 房有关 ${ }^{[9]}$. 除此之外, 在珠江口盆地和粤东地区也零 星分布有少量渐新世火山岩, $\mathrm{K}-\mathrm{Ar}$ 年龄为 $45 \sim 17 \mathrm{Ma}$ (中海油南海东部公司资料). 邹和平等人 ${ }^{[49]}$ 研究了珠 江口盆地玄武岩的微量元素和 Sr-Nd-Pb 同位素特征, 发现其 $\mathrm{Pb}$ 同位素组成具有 Dupal 异常特征. 粤东麒 麟火山岩筒的 $\mathrm{Ar}-\mathrm{Ar}$ 年龄在 $35 \mathrm{Ma}$ (黄小龙等, 未发 表资料), 发育大量幔源包体, 为该地区上地幔热状 态、岩石圈结构和地幔过程提供了研究资料 ${ }^{[10,61,62]}$.

(ii) 南海张开期间(32 16 Ma)的岩浆活动. 迄 今为止, 尚没有在海盆扩张期形成的海底玄武岩的 岩性及年代学数据的正式报道. 这一期岩浆活动的 信息主要来源于早期海底磁条带的研究. 由于磁条

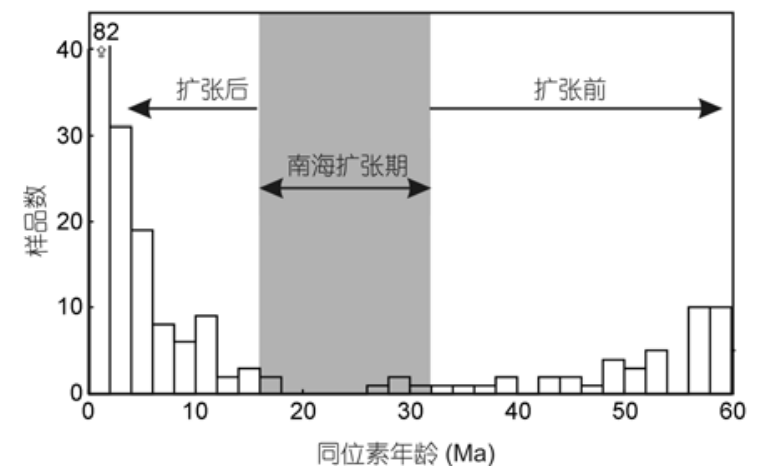

图 4 南海及邻区新生代火山岩的年龄分布直方图及 3 期 岩浆活动

数据来自文献[12,48 60]和黄小龙等人(未发表资料)
带的形成与洋脊扩张过程中新生玄武岩质洋壳有关, 因此在南海发现的磁条带异常 ${ }^{[1,2]}$ 可以看作是南海海 盆张开期间的岩浆活动在磁学上的体现. 海底出现 磁条带异常的范围大致等同于岩浆活动的范围 ${ }^{[11]}$ (图 $1)$, 磁条带形成的时间大致是岩浆活动的时间, 即渐 新世晚期-中新世中期. 获取这一期岩浆活动的岩石 样品是验证南海形成过程与时限的关键. 深海钻探 和特定位置(如正断层)的拖网是关键的突破口.

在南海拉张期期间，南海周边的岩浆活动非常少. 至今只有在粤东的非菜地和普寨等地发现了 20 Ma 的岩浆活动 (黄小龙等, 未发表资料).

(iii) 南海扩张期后( $<16 \mathrm{Ma})$ 的岩浆活动. 在中 央海盆呈东西向展布、在西南次海盆呈北东向展布 的、以及在南海零星分布的海山均属于这一期岩浆活 动(图 1 和 4 ). 王贤觉等人 ${ }^{[50]}$ 最早报道了南海海盆 3 个拖网玄武岩样品的 $\mathrm{K}-\mathrm{Ar}$ 和 ${ }^{40} \mathrm{Ar} /{ }^{39} \mathrm{Ar}$ 年龄, 分别为 13.8, 9.9 和 3.5 Ma. 礼乐滩(Reed Bank)东侧北坡拖网 玄武岩的 $\mathrm{K}-\mathrm{Ar}$ 年龄非常年轻, 为 $2.7 \sim 0.4 \mathrm{Ma}^{[51]}$. 鄢 全树等人 ${ }^{[52]}$ 也报道了该区玄武岩年龄数据, 全岩 $\mathrm{K}-\mathrm{Ar}$ 年龄为 7.91 3.80 Ma.

最近, 韩喜球 ${ }^{[33]}$ 报道了采自南海西南次海盆的几 块似 MORB 玄武岩, 其 $\mathrm{K}-\mathrm{Ar}$ 年龄约为 11.5 3.4 Ma. 这 些玄武岩的年龄低于南海海底扩张停止年龄(15.5 Ma). 如果数据可信的话, 那么南海盆海底的扩张历史就 要改写. 当然海底玄武岩经过长期的海水浸泡, 部分 矿物发生蚀变, 并且带人海水的 $\mathrm{K}$, 因此全岩 $\mathrm{K}-\mathrm{Ar}$ 年龄偏年轻的可能性是存在的. 显然, 尚需进一步的 工作才能解决这一矛盾.

这一期岩浆活动同样广泛发育在南海周边的陆 地上, 如海南岛、雷州半岛、泰国、越南等(图 1). 由 于年代新, 陆上样品采集相对容易, 因此这一期岩浆 的研究资料最多. 该期火山岩喷发经历两个阶段 ${ }^{[63]}$, 早期通过拉张断裂进行的大规模溢流式喷发, 形成 石英拉斑玄武岩及橄榄拉斑玄武岩, 形成了南海及 周边火山岩的主要岩石序列; 之后为火山中心式的 零散喷发, 形成碱性橄榄玄武岩及碧玄岩. 某些样品 含上地幔一下地壳捕虏体.

雷琼地区大面积出露晚新生代火山岩, 面积达 $7000 \mathrm{~km}^{2}$ 以上, 从收集的 86 个年龄数据 ${ }^{[5457]}$ 来看, 其中 54 个年龄数据为更新世, 14 个为上新世, 15 个为 中新世, 渐新世 2 个和始新世 1 个(图 4). 南海北缘中 的北部湾盆地碱性玄武岩 $\mathrm{K}-\mathrm{Ar}$ 年龄 $5.9 \sim 2.4 \mathrm{Ma}^{[58]}$ 也 
应属该期岩浆活动。

在南海西侧的越南南部、老挝南部、泰国南部 Khorat 高原以及柬埔寨东南部也发育大量的晚新生 代火山岩. 早期的 K-Ar 和裂变径迹年龄为 12 0 $\mathrm{Ma}^{[59]}$. Lee 等人 ${ }^{[12]}$ 对越南境内 41 个火山岩进行了 $\mathrm{Ar}-\mathrm{Ar}$ 定 年, 大致厘定出 3 个岩浆活动阶段: 15.5 10.5 Ma, 岩 性主要为石英拉斑玄武岩; 8 5 Ma, 岩性由石英拉斑 玄武岩逐渐过渡到橄榄拉斑玄武岩; 最晚一期的岩 浆在上新世-第四纪之间, 以碱性-强碱性玄武岩为主. 越南岩浆活动的时间与海南-雷州半岛的基本吻合, 其中最早的活动时间与南海扩张结束的时间大致一 致. 显然这不是巧合, 而是反映了南海及邻区岩浆热活动中心由海盆的洋中脊向周边大陆边缘的迁移, 或者是地幔柱活动在不同时空背景下的反映.

\section{2 南海及邻区火山岩的地球化学特征}

在全碱-硅图解(TAS)(图 5)上, 南海张开前的岩
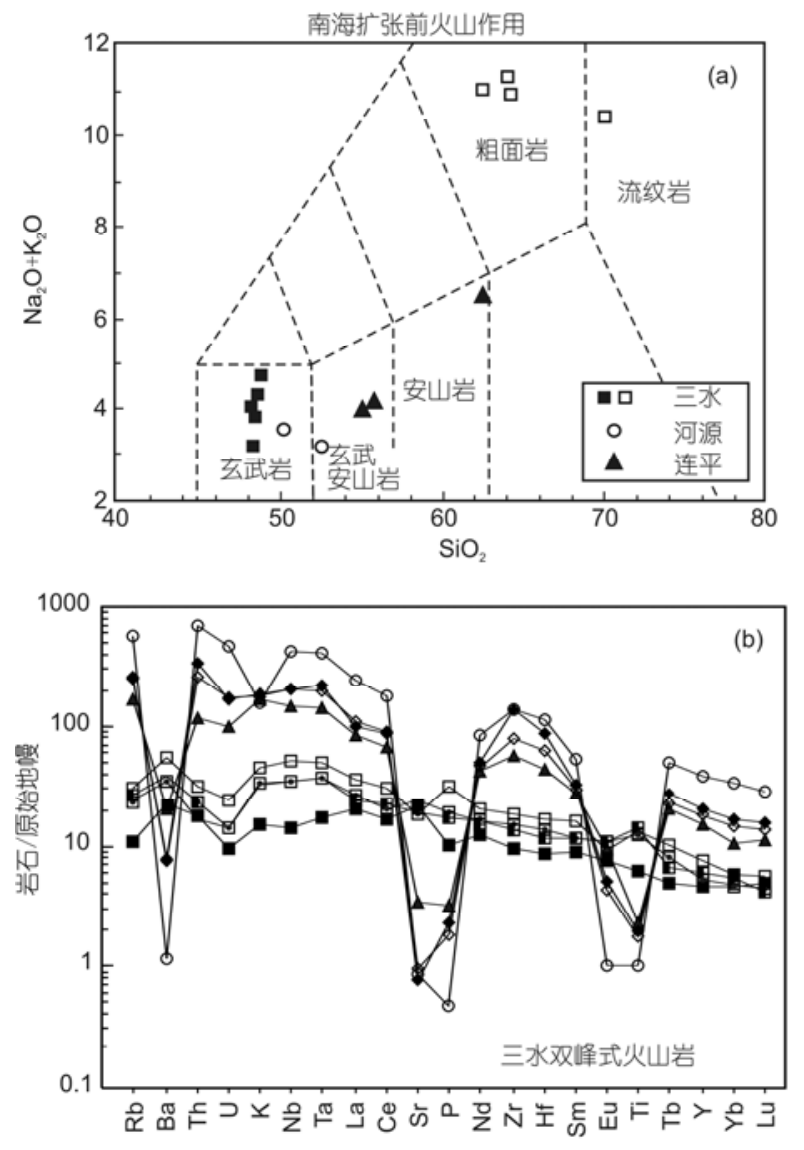

浆成双峰式分布，即由大陆拉斑玄武岩和粗面岩组 成, 其 $\mathrm{Sr}-\mathrm{Nd}$ 同位素比值分别在 $0.705 \sim 0.711, \varepsilon_{\mathrm{Nd}}=+6 \sim$ -5 . 南海张开后的岩浆大部分落在玄武岩、玄武质安 山岩、粗面玄武岩区域. 部分落人碧玄岩和碱玄岩区, 但大部分分布在碱性和亚碱性过渡区(图 5(c)). 这些 玄武岩具有富集大离子亲石元素(LILE), 高场强元 素(HFSE)和轻稀土元素(LREE)的特征, 正的 $\mathrm{Ta}, \mathrm{Nb}$ 异常，原始地幔标准化的不相容元素分配模式类似 于具有 Dupal 同位素异常的洋岛玄武岩(OIB)(图 5(d)).

在同位素相关图解上，南海及周边火山岩有以 下两个特征:

(1) 在 ${ }^{207} \mathrm{~Pb} /{ }^{204} \mathrm{~Pb}$ 对 ${ }^{206} \mathrm{~Pb} /{ }^{204} \mathrm{~Pb}$ 和 ${ }^{208} \mathrm{~Pb} /{ }^{204} \mathrm{~Pb}$ 对 ${ }^{206} \mathrm{~Pb} /{ }^{204} \mathrm{~Pb}$ 图(图 6)中显示有 $\mathrm{DMM}$ 和 $\mathrm{EM} 2$ 端元的二 元混合. ${ }^{143} \mathrm{Nd} /{ }^{144} \mathrm{Nd}$ 和 ${ }^{206} \mathrm{~Pb} /{ }^{204} \mathrm{~Pb}$ 之间负相关, 以及 ${ }^{87} \mathrm{Sr} /{ }^{86} \mathrm{Sr}$ 和 ${ }^{206} \mathrm{~Pb} /{ }^{204} \mathrm{~Pb}$ 之间正相关, 同样反映 $\mathrm{DMM}$ 和 EM2 之间的混合. 这一特征同样见于采自台湾海 峡 $^{[68,69]}$, 越南 ${ }^{[70]}$, 泰国 ${ }^{[71],}$ 澳大利亚 ${ }^{[46]}$ 等地的晚新
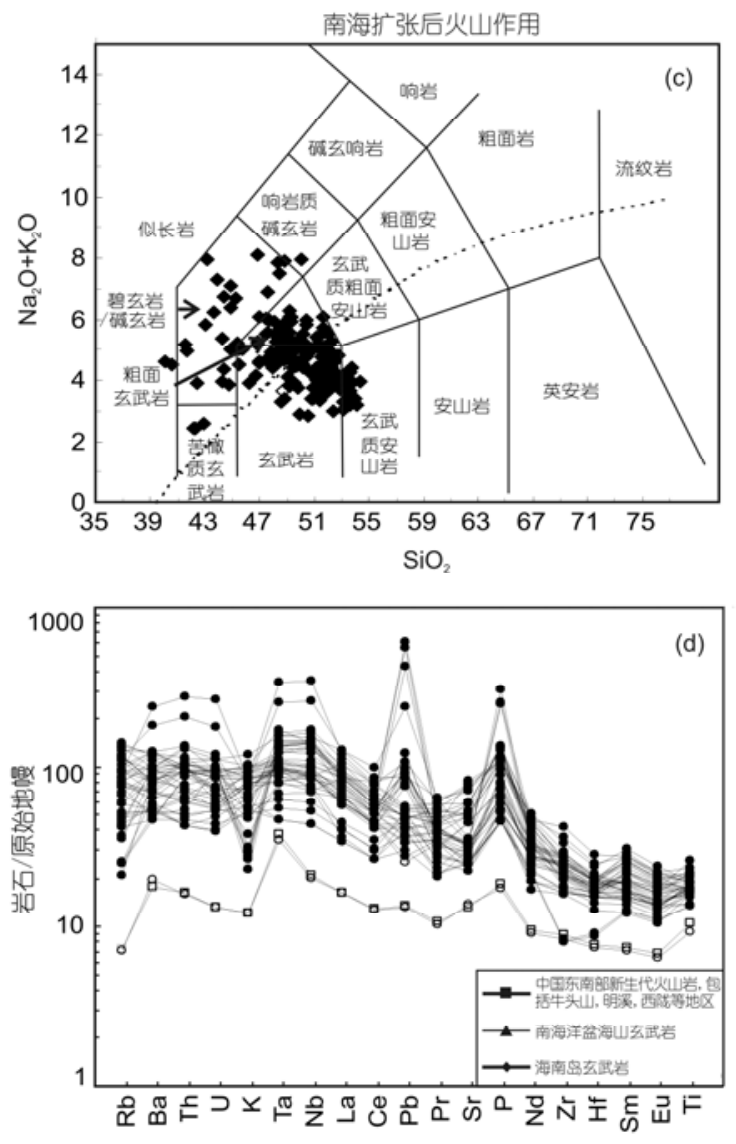

图 5 南海及邻区新生代火山岩的 TAS 图解(a)和微量元素蛛网图(b)

数据来自文献[9,63,64]. 标准化数据据文献[65] 

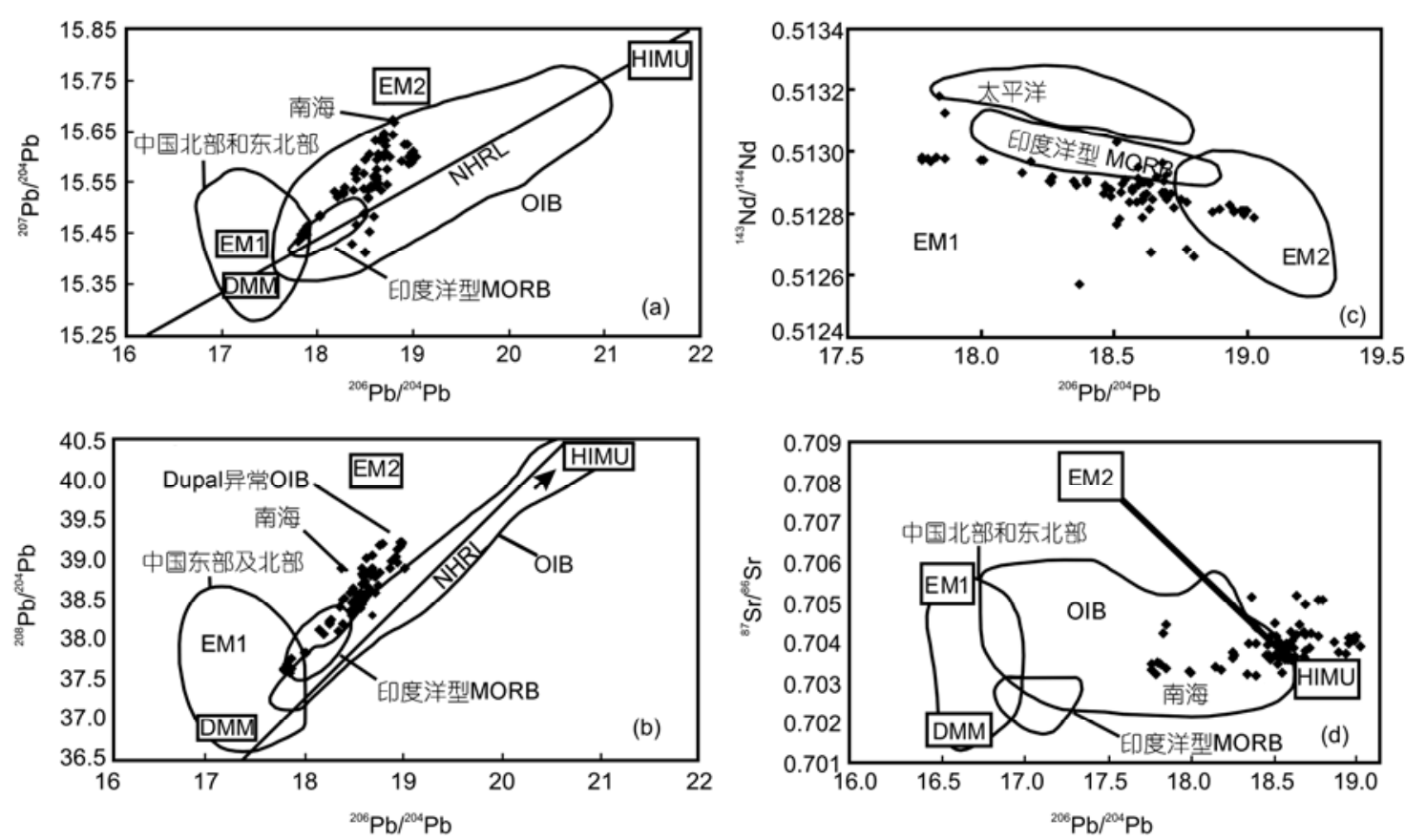

图 6 南海及邻区张开期后(Post-spreading) 火山岩的 ${ }^{207} \mathrm{~Pb} /{ }^{204} \mathrm{~Pb}$ 对 ${ }^{206} \mathrm{~Pb} /{ }^{204} \mathrm{~Pb}(\mathrm{a}),{ }^{208} \mathrm{~Pb} /{ }^{204} \mathrm{~Pb}$ 对 ${ }^{206} \mathrm{~Pb} /{ }^{204} \mathrm{~Pb}(\mathrm{~b}),{ }^{143} \mathrm{Nd} /{ }^{144} \mathrm{Nd}$ 和 ${ }^{206} \mathrm{~Pb} /{ }^{204} \mathrm{~Pb}(\mathrm{c})$ 及的 $\mathrm{Sr} /{ }^{86} \mathrm{Sr}$ 和 ${ }^{206} \mathrm{~Pb} /{ }^{204} \mathrm{~Pb}(\mathrm{~d})$

数据来自文献 $[9,64,66,67]$

生代玄武岩.

(2) 相对于大部分 MORB 而言, 南海及周边火 山岩相对于给定的 ${ }^{206} \mathrm{~Pb} /{ }^{204} \mathrm{~Pb}$ 具有高的 ${ }^{87} \mathrm{Sr} /{ }^{86} \mathrm{Sr}$, ${ }^{207} \mathrm{~Pb} /{ }^{206} \mathrm{~Pb}$ 和 ${ }^{208} \mathrm{~Pb} /{ }^{206} \mathrm{~Pb}$ 比值, 显示 Dupal 同位素异 常(图 6) ${ }^{[64,72]}$.

\section{3 对南海演化的初步认识}

\section{1 南海的扩张历史}

由上可知, 目前在南海海域获取的火山岩样品 绝大多数是 Post-spreading 玄武岩, 以 OIB 型的碱性 和拉斑玄武岩为主. 唯一例外的是韩喜球 ${ }^{[53]}$ 最近报 道的采自南海西南次海盆的几块似 MORB 玄武岩, 但其年龄和确切的地质意义尚需要做进一步的研究. 南海扩张期岩浆样品的缺乏使我们尚不能对南海扩 张历史提供准确的约束.

华南中生代基性岩浆活动集中在陆内, 如分布 在赣南、湘南和闽西一带 ${ }^{[73,74]}$, 至中生代末-新生代, 基性岩浆活动的中心有向东南大陆边缘和南部边缘 迁移的趋势, 在三水、连平、河源和珠江口形成火山 盆地 ${ }^{[9,48]}$. 南向的大陆边缘裂解过程可能是南海扩张
的前奏 ${ }^{[9]}$. 关于南海张开最流行的模式是逃逸模式. Tapponnier 等人 ${ }^{[75]}$ 认为欧亚与印度板块的碰撞导致 印支块体沿红河-哀牢山断裂侧向挤出, 从而导致了 南海的张开. 但哀牢山剪切带的热年代学研究显示, 走滑的时间晚于南海张开的时间 ${ }^{[76]}$, 与逃逸模式的 预测相矛盾.

35 Ma 麒麟火山岩筒中橄榄岩-辉石岩包体显示 较高的地温梯度 ${ }^{[62]}$, 橄榄岩包体的微量元素组成揭 示该区上地幔经历了变压熔融过程 ${ }^{[10]}$, 可能说明岩 石圈扩张盛期应在新生代早期. 此外, 40 50 Ma 的岩 浆中的 $\mathrm{Yb}$ 含量要高于 20 Ma 的岩浆(图 7), 对应于 岩浆起源深度的逐渐加深, 可能与区域岩石圈伸展 至新生代中期逐渐减弱有关. 这说明华南大陆边缘 伸展的持续时间在 40 至 50 20 Ma 之间, 这与根据沉 积幅度和速率获得的主拉张时限 $(45 \sim 25 \mathrm{Ma})^{[77]}$ 大致 一致.

关于非火山型裂解边缘(non-volcanic rifted margin), 其扩张-裂解机制尚不十分清楚. 根据珠江口盆 地和北部湾盆地钻孔资料和模拟, Clift 等人 ${ }^{[77]}$ 发现 华南大陆边缘下地壳具有很小的黏滞系数, 因此华 南大陆边缘裂解可能与该区岩石圈强度变弱有关, 


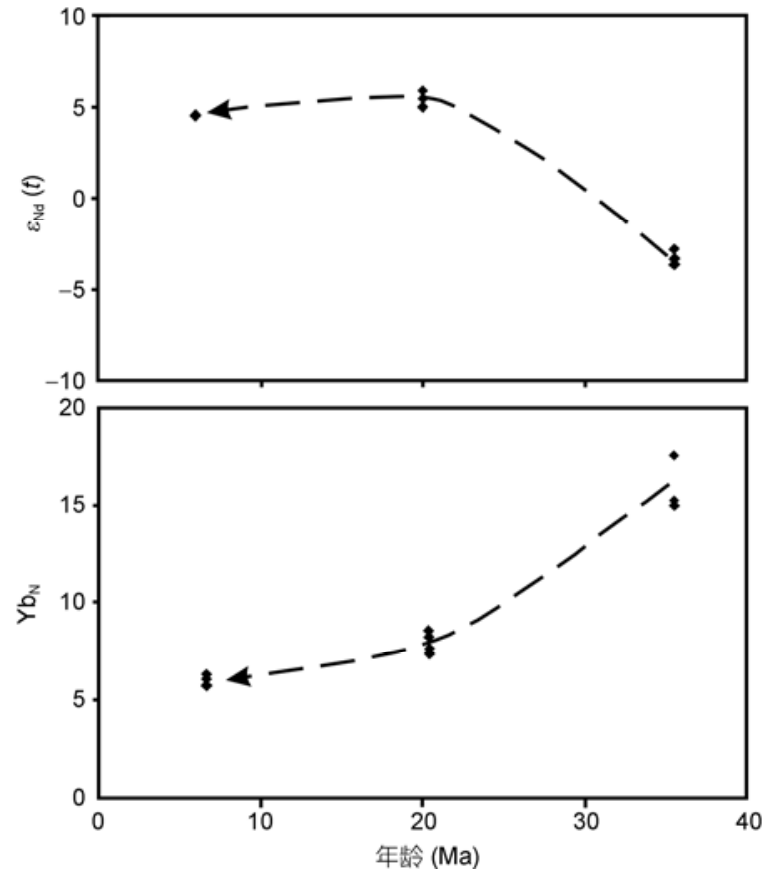

图 7 南海及邻区新生代火山岩的 $\varepsilon_{\mathrm{Nd}}$ 和 $\mathbf{Y b}$ 随时间的 变化趋势

但 Yan 等人 ${ }^{[11]}$ 有不同的看法.

\section{2 海南地幔柱及其与南海扩张的关系}

Lebedev 和 Nolet ${ }^{[5]}$ 及 Montelli 等人 ${ }^{[6]}$ 在海南岛周 围识别到了近直立的地幔柱, 而且低速异常可以延 伸到地表以下 $1900 \mathrm{~km}$ (即中地幔深度), 这显示海南 岛地幔柱起源于下地幔. Zhao ${ }^{[78]}$ 和 Lei 等人 ${ }^{[7]}$ 也提出 在海南岛附近存在地幔柱, 而且认为海南岛地幔柱 是 12 个起源于核幔边界的地幔柱之一, 在上地幔和 下地幔都具有可见的连续低速异常. 那么海南地幔 柱活动的岩石学证据有哪些?

鄢全树和石学法 ${ }^{[8]}$ 根据南海新生代碱性玄武岩中 的橄榄石-流体平衡所推导的地幔潜在温度 $\left(1661^{\circ} \mathrm{C}\right)$, 高出正常地幔 $360^{\circ} \mathrm{C}$. Wang 等人 ${ }^{[79]}$ 发现海南晚新生 代玄武岩中橄榄石斑晶的 Fo 含量高达 $90.7 \%$, 指示 原始岩浆的 $\mathrm{MgO}$ 含量达约 16\% 18\%, 估算的地幔潜 能温度为 $1541 \pm 10^{\circ} \mathrm{C}$, 高出正常地幔 $260^{\circ} \mathrm{C}$. Hoang 和 Flower ${ }^{[70]}$ 计算了越南新生代玄武岩的熔融温压条件, 在不含水条件下, 玄武岩的熔融潜温为 $1400 \sim 1470^{\circ} \mathrm{C}$, 压力为 $<0.5 \sim 4 \mathrm{GPa}$, 而在含水不饱和的条件下, 熔融 潜温为 $1350 \sim 1450^{\circ} \mathrm{C}$, 压力为 $<1.5 \sim 3.5 \mathrm{GPa}$. 虽然不 同作者之间的结论还存在差异，但较高的地幔潜温
显示在南海下伏地幔存在地热异常. 此外, 类似于 OIB 的地球化学特征也与地幔柱模型不矛盾. 如在 $\mathrm{Ta} / \mathrm{Hf}$ vs. Th/Hf 图解(图 8)中, 南海及周边火山岩大 多落在地幔柱玄武岩区域.

对于 EM2 组分的 Dupal 异常的来源尚有不同的 认识. Hart ${ }^{[72]}$ 早期指出 Dupal 异常的地幔主要分布在 南半球, 在北半球及两极地区基本上不存在. 但是随 着研究的深人, 逐渐发现 Dupal 异常不只存在于南半 球, 南海及周边认为是北半球少数具有 Dupal 异常的 地区之一[63,64,80,81]. 有学者认为 Dupal 异常特征可能 是由于中国东南部曾经属于主要分布在南半球的冈 瓦纳大陆 ${ }^{[81]}$. 古地磁学证据表明在晚古生代, 中国 东南部曾发生向北的迁移 ${ }^{[82]}$, 南海及周边玄武岩的 Dupal 异常则继承自冈瓦纳大陆. 这一解释的不足之 处在于, 超大陆的形成与裂解一般局限于岩石圈深 度，大规模的软流圈地幔的对流与超大陆漂移之间 是否存在耦合关系尚不清楚. 例如, 古地磁学和古气 候学表明, 华北地块属于主要分布在北半球的劳伦

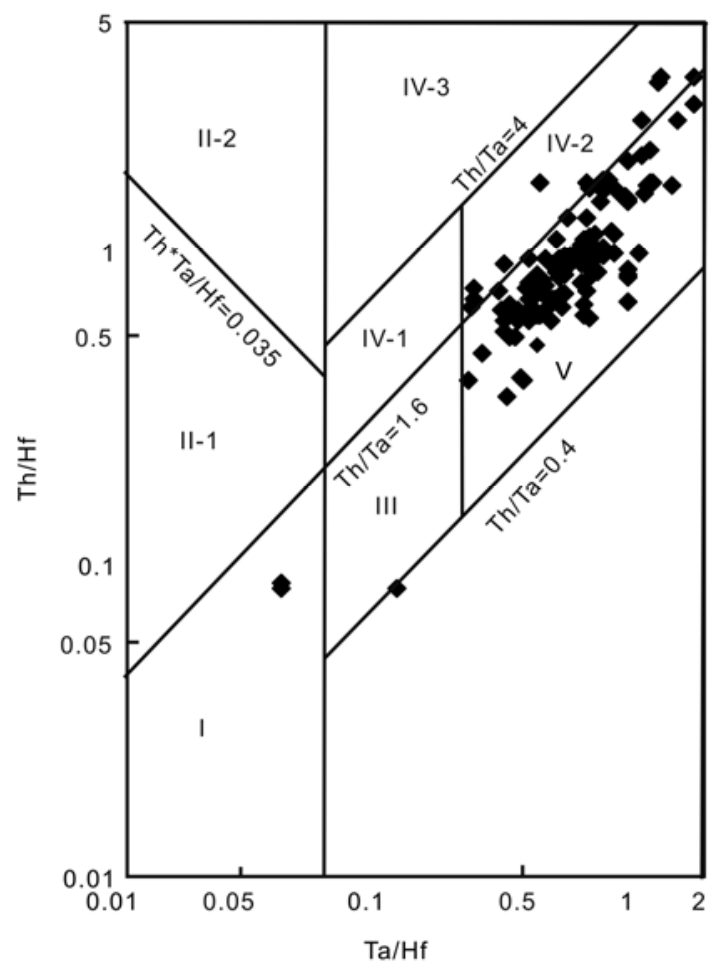

图 8 南海及邻区 Post-spreading 火山岩的 $\mathrm{Ta} / \mathrm{Hf}$ vs. Th/Hf 图解

I, NMORB; II, 汇聚板块边缘; II-1, OIB; II-2, 大陆边缘弧和火山岛 弧玄武岩; III, 洋岛和海山玄武岩, TMORB 和 EMORB; IV, 板内构 造背景; $\mathrm{V}$, 地幔柱玄武岩数据来源同图 6 
古陆的一部分 ${ }^{[82,83]}$, 但该地区新生代玄武岩同样具 有高的 ${ }^{208} \mathrm{~Pb} /{ }^{204} \mathrm{~Pb}$ 和 ${ }^{207} \mathrm{~Pb} /{ }^{204} \mathrm{~Pb}$ 的 Dupal 异常的特征.

该区 Dupal 异常可能与循环陆壳或者地幔岩石 圈物质的混人有关 ${ }^{[64]}$. 华南地幔岩石圈普遍具有 HFSE 亏损的特征 ${ }^{[10,84]}$, 而南海及周边玄武岩则具有 HFSE 富集的特征. 由于南海岩石圈较薄 ${ }^{[85]}$, 而且在 玄武岩喷发过程中发生了减薄作用 ${ }^{[2]}$, 在南海发生玄 武岩喷发的时候认为基本不存在古老的岩石圈地幔, 所以认为南海及周边玄武岩的 EM2 端元组分不太可 能来自南海岩石圈地幔物质的混人.

由于 $\mathrm{Pb}$ 在亏损地幔含量极低而在地壳中相对较 高 ${ }^{[86]}$, 所以 $\mathrm{Pb}$ 同位素体系一般是对地壳物质加人最 敏感的同位素体系. White 和 Dupre ${ }^{[87]}$, Mukasa 等人 ${ }^{[88]}$ 认为 Dupal 异常是俯冲作用造成的壳源物质混人. 朱 炳泉和王慧芬 ${ }^{[54]}$ 以及 Zhang 等人 ${ }^{[66,89]}$ 也认为雷琼地 区地幔源区可能与古俯冲带带人的沉积物有关. 地 幔源区中的俯冲组分更可能与地幔柱中地壳再循环 组分有关, 即与海南地幔柱紧密相关. Zou 和 $\mathrm{Fan}^{[81]}$ 利用年轻南海及周边玄武岩 $(\sim 9000 \mathrm{a})$ 的 ${ }^{230} \mathrm{Th} /{ }^{238} \mathrm{U}$ 估 算了海南岛地幔柱的上涌速率, 得出总体地幔上涌 速率 $<1 \mathrm{~cm} / \mathrm{a}$ ，明显慢于夏威夷地幔柱上涌速率(10 $30 \mathrm{~cm} / \mathrm{a})^{[00]}$.

如果海南地幔柱的确存在的话，一个相关的问 题是, 地幔柱活动是否导致了南海的张开? 由于目 前关于地幔柱活动的时限还没有很好的约束, 这一 问题也就没有明确的答案.

世界上 $90 \%$ 以上的大陆边缘属于火山裂解边缘 (volcanic rifted margin), 其最主要的特征包括: 大火 成岩省, 陆-洋过渡带存在高速下地壳(HVLC)以及海 向一侧存在反射系列 $(\mathrm{SDRS})^{[91]}$. 从南海北缘火山分 布的规模以及现有深部地震剖面来看, 华南大陆边 缘不具备这些特点, 似乎暗示南海的张开与地幔柱 关系不大 ${ }^{[52]}$. 同样, 这一地区所有 OIB 型玄武岩均 属南海拉张期后的岩浆活动, 因此即使这些岩浆活 动是海南地幔柱的产物, 说明地幔柱可能不是南海 张开的主要原因. 这一结论的不确定性在于, 火山裂 解边缘的形成并不一定与地幔柱有关 ${ }^{[92]}$, 而地幔柱 形成的岩浆并不一定具有 OIB 的特点, 尤其是在洋 中脊-地幔柱相互作用的情形下(见下).

根据南海及周边地区岩浆活动的时空分布(图 4), 可构思如下两种动力学模型.

(1) 南海扩张与地幔柱活动是两个相互独立事
件. 南海扩张期间岩浆活动来自于对流地幔的减压 熔融. 南海的扩张造成了周缘板块处于挤压环境, 因 此岩浆活动只出现在南海海盆. 而当南海扩张停止 后, 周缘板块的应力得到释放, 引发南海及周边地区 上地幔的熔融.

(2) 南海及周边地区新生代岩浆活动均与地幔 柱有关. 在南海扩张期间, 由于洋脊抽吸(ridge suction)效应 ${ }^{[13]}$, 地幔柱流集中流向南海洋中脊 (图 9), 因此岩浆活动集中在南海海盆. 当南海扩张停止后, 洋脊吸引效应不再存在, 地幔柱活动形成的岩浆出 现在南海及周边地区. 如果这一模式正确的话, 即海 南地幔柱上涌的位置与南海洋中脊重叠, 其构造背 景类似于现今大西洋中的冰岛(冰岛地幔柱与大西洋 洋中脊的位置重叠). 在这种背景下地幔柱与洋中脊 的相互作用是不可避免的, 南海扩张期产出的岩浆 可能并不是典型的 MORB 岩浆, 而应是间于 OIB 与 MORB 之间的过渡类型, 且在一定程度上岩浆成分呈 现有规律的变化(图9). 这可在今后工作中加以验证.

\section{4 研究设想}

在南海及其周边广泛发育的火山活动记录了南 海演化以及相关的深部动力学过程的重要信息, 然 而，目前这些火山岩的岩石属性、形成时代和相关的 动力学机制尚不十分清楚. 造成该领域研究十分薄 弱的原因有两个:

(1) 南海火山岩样品的获取存在困难, 零星的拖 网玄武岩样品虽然十分珍贵，而且可以给出年龄和 地球化学属性, 但由于缺乏样品产出构造位置的精 确确定，样品的时空分布远达不到系统的程度，难以 满足约束南海形成过程的要求.

(2) 将现代火山岩研究与深部动力学过程的联 系不够, 多数研究均停留在个别年龄和岩性的报道, 尚无从整体的角度阐明地幔过程与南海张裂演化之 间的联系.

为了弥补这些缺陷, 首先必须解决样品的系统 获取问题. 考虑到通过 IODP 实施南海深钻尚需时日 和努力, 本文建议在“南海深海过程演变”重大研究 计划实施过程中, 规划并有效地组织海底火山岩样 品的采集. 建议将中央海盆及以北地区 (见图 10)作为 研究区域, 进行加密的网格状拖网和浅钻采样, 争取 获得中央海盆海山链 $A-B$ 剖面, 和垂直于 $A-B$ 剖面的 $C-D$ 剖面的系统火山岩样品. 理由是: ( i ) 根据 $30 \mathrm{a}$ 


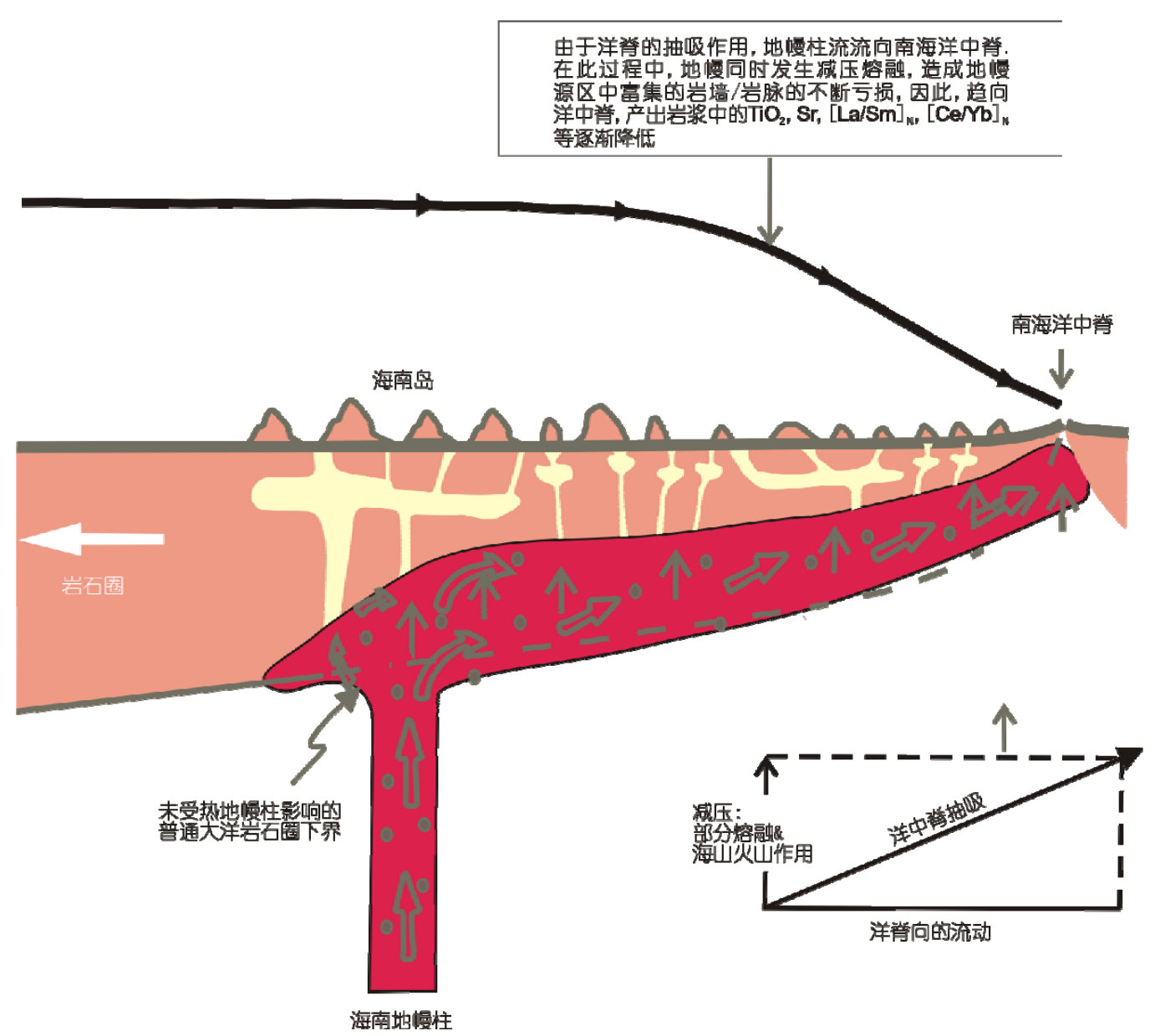

图 9 用于解释南海及周边地区新生代火山岩时空分布(图 4)的洋脊抽吸(Ridge suction)模式 据文献[13]修改

前美国的船测磁异常条带资料, 东西向 $A-B$ 海山的位 置可能是南海张裂过程中的洋中脊, 因此可能记录 了南海张裂的终止时间, 而研究区北侧与大陆架接 触的位置可能是南海张裂早期形成的洋壳, 因此可 能可以约束南海张裂的起始时间; (ii) 南北向 $C-D$ 剖面的样品则可能记录了南海张裂过程的整个历史; (iii) 这一地区海山发育, 距海平面相对较浅, 以利 于拖网采样的实施.

\section{1 南海海盆的张裂历史}

(1) 如果系统的拖网采样获得的是 MORB, 那么 沿 $C-D$ 剖面开展高精度的 $\mathrm{Ar}-\mathrm{Ar}$ 年代学工作, 可获得 南海扩展的起始和终结时间, 这是构建南海形成模 式的关键, 也可为本重大研究计划中磁条带和深部 地球物理研究提供相互印证的机会. 通过年代学数 据和洋盆大小可以计算洋中脊扩张速率. 前人已发
现 MORB 组成与洋中脊扩张速率存在一定的相关 性 ${ }^{[18]}$, 因此从火山岩成分的角度同样也可以制约洋 中脊扩张速率.

（2）考虑到南海水深, 沉积物厚度大, 获取 MORB 样品存在较大的不确定性. 只有在断层附近有可能获 得因构造运动抬升至沉积物表面的 MORB 样品. 因 此拖网采样获得的海山样品更可能是南海扩张以后 形成的 OIB 型岩浆. 与 MORB 样品不同, 这类岩石 (特别是南北向 $C-D$ 剖面的样品, 图 10) 可以间接用于 制约南海的演化过程. 南海火山岩大多数来源于软 流圈地幔 ${ }^{[64]}$, 假定火山岩源区一致的话, 那么其成 分主要与熔融深度有关, 因此根据玄武岩的成分可 确定地幔起始熔融深度和终止熔融深度, 进而可反 演火山形成时岩石圈的厚度. 这一工作可以帮助我 们验证: (1) 从 $C \rightarrow D$ 岩石圈厚度是否逐渐增加(图 11), 这是南海洋盆扩张模型所要求的; (2) 大洋背景中新 


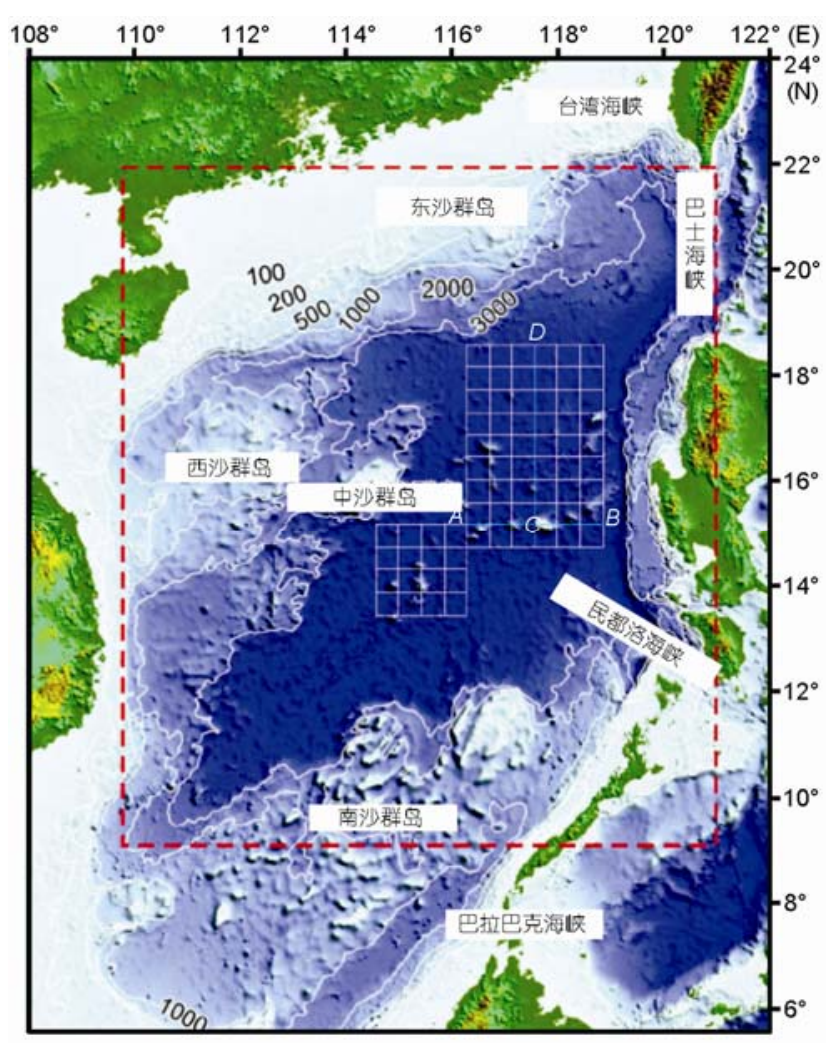

图 10 建议的南海海底拖网采样方案 等深线单位: $\mathrm{m}$

生岩石圈的厚度与其形成时间的平方根之间存在正相 关关系 ${ }^{[93 ~ 97]}$, 因此根据 $C-D$ 剖面岩石圈厚度可以计算
出岩石圈的形成年龄, 再扣除火山岩的年龄后, 就可 以估算出南海洋盆形成的起始和终止时间.

据文献[21]修改. $C$ 对应于南海最年轻的洋中脊 位置, 按照南海洋盆扩张模型, $C \rightarrow D$ 岩石圈厚度应 逐渐增加. 在这一岩石圈背景下产生的岩浆成分受 控于地幔潜能温度和岩石圈的厚度. 由于大洋岩石 圈的厚度与其形成时间的平方根之间存在正相关关 系，因此根据岩浆成分获得的 $C-D$ 剖面岩石圈厚度 可以计算出岩石圈的形成年龄，再扣除火山岩的年 龄后, 可估算出南海洋盆形成的起始和终止时间.

\section{2 南海地幔柱的岩石学验证}

除了对南海海盆的张裂历史提供制约外，系统 火山岩采样还可以帮助我们研究另外一个重要的科 学问题, 即南海是否存在地幔柱, 如有, 地幔柱活动 在南海张裂过程中扮演了什么样的角色. 可从以下 3 个角度开展研究.

(1) $A-B$ 剖面代表了南海海域中线性分布最为特 征的海山, 对该剖面样品系统的、高精度的 Ar-Ar 同 位素定年, 可以帮助我们判断从 $A \rightarrow B$ 火山年龄是否 顺序变化, 是否与产出位置存在线性关系. 如发现与 夏威夷岛链一样的规律, 将是南海存在地幔柱有力 的证据.

（2）地幔柱活动的一个重要特征是地幔潜能温

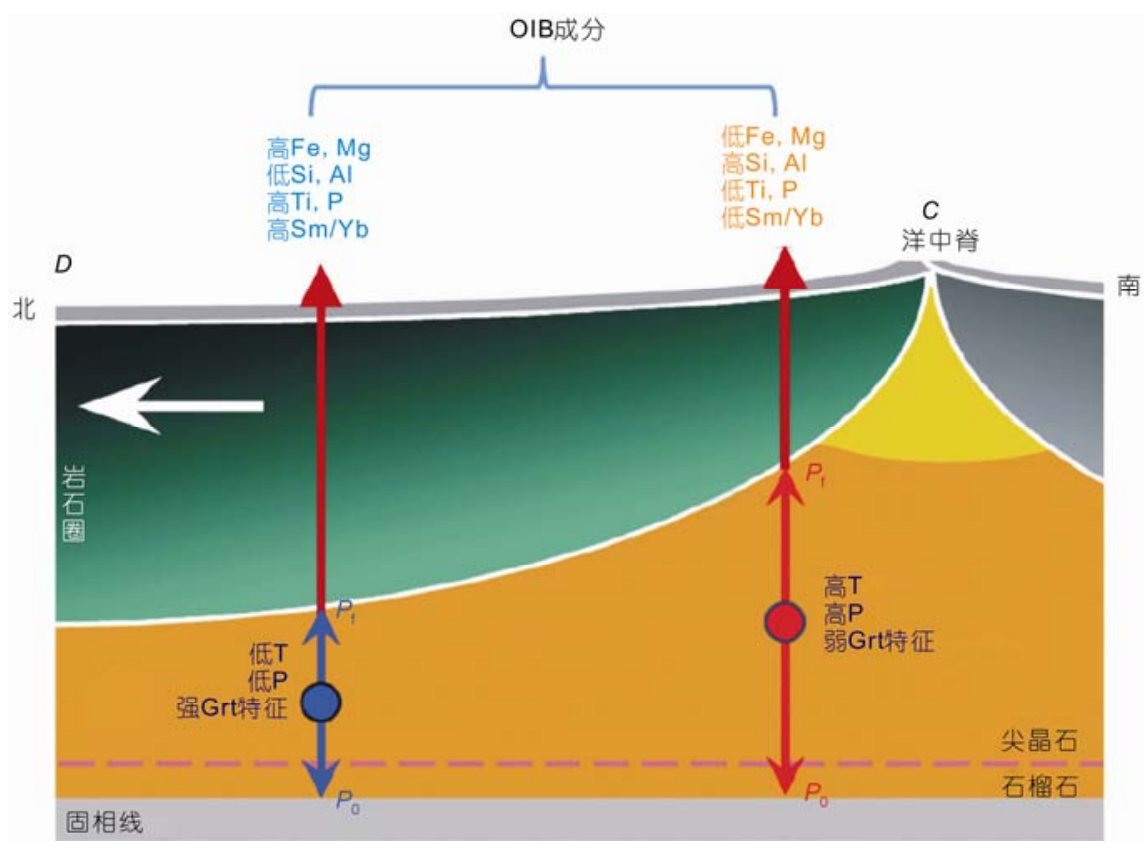

图 11 沿图 10 中 $C-D$ 方向推测的岩石圈结构示意图 
度高于正常地幔 $200^{\circ} \mathrm{C}$ 左右. 原始岩浆的成分与地 幔潜能温度之间存在相关关系, 因此如能准确确定 原始岩浆的成分就能确定地幔潜能温度. 火成岩的 全岩成分是一系列复杂过程(源区不均一性、岩浆的 混合、结晶分异等)的最终产物, 因此难以保存原生 岩浆的成分 ${ }^{[98,99]}$. 岩浆中较早结晶的橄榄石内的熔 融包裹体却较好地记录了原生岩浆的成分 ${ }^{[100]}$. 与全 岩相比, 橄榄石中的熔体包裹体具有如下优点. ( i ) 由于橄榄石是在玄武质岩浆中最早结晶的矿物之一, 同时早期结晶的橄榄石具有富 $\mathrm{MgO}$ 的特征, 因此高 Fo 值的橄榄石中的熔体包裹体可能保存岩浆演化之 前的原始熔体成分信息; (ii) 橄榄石中不相容元素 的含量非常低, 因此, 橄榄石对熔体包裏体的微量元 素含量的影响可以忽略不计. 因此对南海海山火山 岩中橄榄石斑晶中熔融包裹体进行系统研究, 可帮 助限定原始岩浆的成分, 从而限定地幔的潜能温度.

(3) 采用“岩石探针”和同位素示踪技术，通过对
南海海山火山岩系统的岩石地球化学研究, 了解岩 浆源区特征、物质组分与熔融机制, 分析不同起源岩 浆系统的演化过程及其记录的壳/幔相互作用，特别 是鉴别岩浆中软流圈-地幔柱-岩石圈-地壳组分, 并 定量评估其在岩浆中的贡献，结合与世界上典型地 幔柱成因火山岛链的对比, 为回答南海是否存在地 幔柱提供关键资料.

\section{3 洋中脊-地幔柱相互作用}

如果南海存在洋脊扩张, 并经历了地幔柱作用, 那么洋中脊-地幔柱相互作用是不可避免的. 在这种 背景下产出的岩浆不是典型的 MORB 岩浆, 而且洋 脊吸引效应可形成有规律的成分变化(图 9). 系统的 样品采集可帮助我们鉴别这一模式.

总之, 目前关于南海演化的假说-猜测多于结论, 相信随着“南海深海过程演变”重大研究计划的实施, 这种局面将会改变.

\section{参考文献}

1 Taylor B, Hayes D E. Origin and history of the South China Sea basin. In: Dennis E, Hayes D E, eds. The Tectonic and Geologic Evolution of South Eastern Asian Seas and Islands. AGU Geophysical Monograph, 1983. 23-56

2 Briais A, Patriat P, Tapponnier P. Updated interpretation of magnetic anomalies and seafloor spreading stages in the South China Sea: Implications for the Tertiary tectonics of Southeast Asia. J Geophys Res, 1993, 98: 6299-6328

3 Kido Y, Suyehiro K, Kinoshita H. Rifting to spreading process along the northern continental margin of the South China Sea. Mar Geophys Res, 2001, 22: 1-15

4 Hsu S K, Yeh Y C, Doow B, et al. New bathymetry and magnetic lineations identification in the northernmost South China Sea and their tectonic implications. Mar Gephys Res, 2004, 25: 29-44

5 Lebedev S, Nolet G. Upper mantle beneath southeast Asia from S velocity tomography. J Geophys Res, 2003, 108: 20-48

6 Montelli R, Nolet G, Dahlen F A, et al. Finite-frequency tomography reveals a variety of plumes in the mantle. Science, 2004, 303: 338-343

7 Lei J S, Zhao D P, Steinberger B, et al. New seismic constraints on the upper mantle structure of the Hainan plume. Phys Earth Planet Inter, 2009, 173: 33-50

8 鄢全树, 石学法. 海南地幔柱与南海形成演化. 高校地质学报, 2007, 13: 311-322

9 Chung S L, Cheng H, Jahn B M, et al. Major and trace element, and Sr-Nd isotope constraints on the origin of Paleogene volcanism in South China prior to the South China Sea opening. Lithos, 1997, 40: 203-220

10 Xu Y G, Sun M, Yan W, et al. Xenolith evidence for polybaric melting and stratification of the upper mantle beneath South China. J Asian Earth Sci, 2002, 20: 937-954

11 Yan P, Deng H, Liu H L, et al. The temporal and spatial distribution of volcanism in the South China Sea region. J Asian Earth Sci, 2006, 27: 647-659

12 Lee T Y, Lo C H, Chung S L, et al. ${ }^{40} \mathrm{Ar} /{ }^{39} \mathrm{Ar}$ dating result of Neogene basalts in Vietnam and its tectonic implication. In: Flower M, Chung S L, Lo C H, et al. eds. Mantle dynamics and plate interactions in East Asia. American Geophysical Union Monograph, 1998, 27: 317-330

13 Niu Y L, Hékinian R. Ridge suction drives plume-ridge interactions (Chapter 9). In: Hékinian R, Stoffers P, eds. Oceanic Hotspots. New York: Springer-Verlag, 2004. 285-307 
14 Niu Y L, Batiza R. An empirical method for calculating melt compositions produced beneath mid-ocean ridges: Application for axis and off-axis (seamounts) melting. J Geophys Res, 1991, 96: 21753-21777

15 Ellam R M. Lithospheric thickness as a control on basalt geochemistry. Geology, 1992, 20: 153-156

16 Langmuir C H, Klein E M, Plank T. Petrological systematics of mid-ocean ridge basalts: constraints on melt generation beneath ocean ridges. In: Morgan J P, Blackman D K, Sinton J M, eds. Mantle Flow and Melt Generation at Mid-ocean Ridges, AGU Geophys Monogr Vol. 71, Washington DC, 1992. 183-280

17 Haase K M. The relationship between the age of the lithosphere and the composition of oceanic magmas: Constraints on partial melting, mantle sources and the thermal structure of the plates. Earth Planet Sci Lett, 1996, 144: 75-92

18 Niu Y L, Hékinian R. Spreading rate dependence of the extent of mantle melting beneath ocean ridges. Nature, 1997, 385: 326-329

19 徐义刚. 用玄武岩组成反演中-新生代华北岩石圈的演化. 地学前缘, 2006, 13: 93-104

20 Humphreys E R, Niu Y L. On the composition of ocean island basalts (OIB): The effects of lithospheric thickness variation and mantle metasomatism. Lithos, 2009, 112: 118-136

21 Niu Y L, Wilson M, Humphreys E R, et al. The origin of intra-plate ocean island basalts (OIB): The lid effect and its geodynamic implications. J Petrol, 2011, 52: 1443-1468

22 Fram M S, Lesher C F. Geochemical constraints on mantle melting during creation of the North Atlantic basin. Nature, 1993, 363: $712-715$

23 McKenzie D, Bickle M J. The volume and composition of melt generated by extension of the lithosphere. J Petrol, 1988, 29: 625-679

24 Menzies M A. Archaean, Proterozoic, and Phanerozoic lithospheres. In: Menzies M A, ed. Continental Mantle. Oxford: Oxford Science Publications, 1990. 67-86

25 徐义刚. 拉张环境中的大陆玄武岩浆作用: 性质及动力学过程. 见: 郑永飞, 编. 化学地球动力学进展. 北京: 科学出版社, 1999 . 119-167

26 DePaolo D J, Daley E E. Neodymium isotopes in basalts of the southwest basin and range and lithospheric thinning during continental extension. Chem Geol, 2000, 169: 157-185

27 Arndt N T, Christensen U. The role of lithospheric mantle in continental flood volcanism - Thermal and geochemical constraints. J Geophys Res, 1992, 97: 10967-10981

28 Jaques A L, Green D H. Anhydrous melting of peridotite at 0-15 kb pressure and the genesis of tholeiitic basalts. Contrib Mineral Petrol, 1980, 73: 287-310

29 Kushiro I. Partial melting experiments on peridotite and origin of mid-ocean ridge basalt. Ann Rev Earth Planet Sci, 2001, 29: 71-107

30 Green D H, Ringwood A E. The "genesis" of basaltic magmas. Contrib Mineral Petrol, 1967, 15: 103-109

31 McKenzie D, O’Nions R K. Partial melt distribution from inversion of rare earth element concentrations. J Petrol, 1991, 32: 1021-1091

32 O'Neill H S C. The transition between spinel lherzolite and garnet lherzolite, and its use as a geobarometer. Contrib Mineral Petrol, 1981, 77: 185-194

33 Robinson J A, Wood B J. The depth of the spinel to garnet transition at the peridotite solidus. Earth Planet Sci Lett, 1998, 164: 277-284

34 Blundy J, Dalton J. Experimental comparison of trace element partitioning between clinopyroxene and melt in carbonate and silicate systems, and implications for mantle metasomatism. Contrib Mineral Petrol, 2000, 139: 356-371

35 Klein E M, Langmuir C H. Global Correlations of Ocean Ridge Basalt Chemistry with Axial Depth and Crustal Thickness. J Geophys Res, 1987, 92: 8089-8115

36 Klein E M, Langmuir C H. Local versus global variations in ocean ridge basalt composition: A replay. J Geophys Res, 1989, 94 : $4241-4252$

37 Niu Y L, O'Hara M J. Global correlations of ocean ridge basalt chemistry with axial depth: A new perspective. J Petrol, 2008, 49: 633-664

38 Kinzler R. Melting of mantle peridotite at pressure approaching the spinel to garnet transition: Application to mid-ocean ridge basalt petrogenesis. J Geophys Res, 1997, 102: 853-874

39 Wang K, Plank T, Walker J D, et al. A mantle melting profile across the basin and range SW USA. J Geophys Res, 2002, 107: ECV 5-1-ECV 5-21

40 张辉煌, 徐义刚, 葛文春, 等. 吉林伊通-大屯地区晚中生代-新生代玄武岩的地球化学特征及其意义. 岩石学报, 2006, 22 1579-1607

41 Campbell I H. Identication of ancient mantle plumes. In: Ernst R E, Buchan K, eds. Mantle Plumes: Their Identication through Time. Geol Soc Am Spe Pap, 2001, 352: 5-22

42 Xu Y G, He B, Huang X L, et al. Testing plume hypothesis in the Emeishan large igneous province. Episodes, 2007, 30: 32-42

43 Hart S R, Hauri E H, Oschmann L A, et al. Mantle plume and entrainment: Isotopic evidence. Science, 1992, 256: 517-520

44 Zindler A, Hart S R. Chemical geodynamics. Ann Rev Earth Planet Sci, 1986, 14: 493-571 
45 Niu Y L, Collerson K D, Batiza R, et al. The origin of E-type MORB at ridges far from mantle plumes: The East Pacific Rise at $11^{\circ} 20^{\prime}$ N. J Geophys Res, 1999, 104: 7067-7087

46 Zhang M, O’Reilly S Y, Chen D G. Location of Pacific and Indian mid-ocean ridge-type mantle in two time slices: Evidence from Pb, Sr, and $\mathrm{Nd}$ isotopes for Cenozoic Australian basalts. Geology, 1999, 27: 39-42

$47 \mathrm{Xu} \mathrm{Y} \mathrm{G,} \mathrm{Zhang} \mathrm{H} \mathrm{H,} \mathrm{Qiu} \mathrm{H} \mathrm{N,} \mathrm{et} \mathrm{al.} \mathrm{Oceanic} \mathrm{crust} \mathrm{components} \mathrm{in} \mathrm{continental} \mathrm{basalts} \mathrm{from} \mathrm{Shuangliao,} \mathrm{Northeast} \mathrm{China:} \mathrm{Derived} \mathrm{from} \mathrm{the}$ mantle transition zone? Chem Geol, 2012, doi: 10.1016/j.chemgeo.2012.01.027

48 Zhu B Q, Wang H F, Mao C X, et al. Geochronology and Nd-Sr-Pb isotopic evidence for mantle source in the ancient subduction zone beneath Sanshui basin, China. Chin J Geochem, 1989, 8: 65-71

49 邹和平, 李平鲁, 饶春涛. 珠江口盆地新生代火山岩地球化学特征及其动力学意义. 地球化学, 1995, 24(Suppl 1): 33-45

50 王贤觉, 吴明清, 梁德华, 等. 南海玄武岩的某些地球化学特征. 地球化学, 1984, 4: 332-340

51 Kudrass H R, Wiedicke M, Cepek P, et al. Mesozoic and Cainozoic rocks dredged from the South China Sea (Reed Bank area) and Sulu Sea and their significance for plate-tectonic reconstructions. Mar Petrol Geol, 1986, 3: 19-30

52 漂全树, 石学法, 王昆山, 等. 南海新生代碱性玄武岩主量、微量元素及 $\mathrm{Sr}-\mathrm{Nd}-\mathrm{Pb}$ 同位素研究. 中国科学 D 辑: 地球科学, 2008, 38: 56-71

53 韩喜球. 南海西南次海盆洋脊玄武岩：南海海底扩张的岩石地球化学和年代学制约. “南海深海过程演变”重大研究计划 2011 年度 学术研讨会暨研究计划启动会议文集, 2011.26-27

54 朱炳泉, 王慧芬. 雷琼地区 MORB-OIB 过渡型地幔源灿作用的 Nd-Sr-Pb 同位素证据. 地球化学, 1989, 18: 193-201

55 陈俊仁, 广东田. 洋火山湖第四纪地质. 北京: 地质出版社, 1990

56 孙嘉诗. 南海北部及广东沿海新生代火山活动. 海洋地质与第四纪地质, 1991, 11: 45-65

57 黄镇国, 蔡福祥, 韩中元, 等. 雷琼第四纪火山. 北京：科学出版社, 1993

58 贾大成, 丘学林, 胡瑞忠, 等. 北部湾玄武岩地幔源区性质的地球化学示踪及其构造环境. 热带海洋学报, 2003, 22: 30-39

59 Barr S M, Macdonald A S. Geochemistry and geochronology of late Cenozoic basalts of Southeast Asia: Summary. Geol Soc Amer Bull, 1981, 92: 508-512

60 Zhu B Q, Wang H F, Chen Y W, et al. Geochronological and geochemical constraint on the Cenozoic extension of Cathaysian lithosphere and tectonic evolution of the border sea basins in East Asia. J Asian Earth Sci, 2004, 24: 163-175

$61 \mathrm{Xu}$ X S, O'Reilly S Y, Zhou X M, et al. Axenolith-derived geotherm and the crust-mantle boundary at Qilin, southeastern China. Lithos, 1996, 38: 41-62

62 Xu Y G, Lin C Y, Shi L B. The geotherm of the lithosphere beneath Qilin, SE China: A re-appraisal and implications for P-T estimation of Fe-rich pyroxenites. Lithos, 1999, 47: 181-193

63 Flower M F J, Zhang M, Chen C Y, et al. Magmatism in the South China Basin. 2. Post-Spreading Quaternary Basalts from Hainan Island, South China. Chem Geol, 1992, 97: 65-87

64 Tu K, Flower M F J, Carlson R W, et al. Magmatism in the South China Basin. 1. Isotopic and Trace-Element Evidence for an Endogenous Dupal Mantle Component. Chem Geol, 1992, 97: 47-63

65 Sun S S, McDonough W F. Chemical and isotopic systematics of oceanic basalts: Implications for mantle composition and processes. In: Saunders A D, Norry M J, eds. Magmatism in the Ocean Basins. Geol Soc London, Spec Publ, 1989, 42: 313-345

66 Zhang M, Tu K, Xie G H, et al. Trace element and isotope geochemistry of Cenozoic basalts from Hainan island. In: Liu R X, ed. Geochronology and Geochemistry of Cenozoic Volcanic Rocks in China. Beijing: Seismic Publishing House, 1992. 246-268

67 Zou H B, Zindler A, Xu X S, et al. Major, trace element, and Nd, Sr and Pb isotope studies of Cenozoic basalts in SE China: Mantle sources, regional variations, and tectonic significance. Chem Geol, 2000, 171: 33-47

68 Chung S L, Sun S S, Tu K, et al. Late Cenozoic basaltic volcanism around the Taiwan Strait, SE China: Product of lithosphere-asthenosphere interaction during continental extension. Chem Geol, 1994, 112: 1-20

69 Chung S L, Jahn B M, Chen S J, et al. Miocene basalts in northwestern Taiwan: Evidence for Em-type mantle sources in the continental lithosphere. Geochim Cosmochim Acta, 1995, 59: 549-555

70 Hoang N, Flower M. Petrogenesis of Cenozoic Basalts from Vietnam: Implication for Origins of a "Diffuse Igneous Province". J Petrol, 1998, 39: 369-395

71 Zhou P B, Mukasa S B. Nd-Sr-Pb isotopic, and majorand trace-element geochemistry of Cenozoic lavas from the Khorat Plateau, Thailand: Source and petrogenesis. Chem Geol, 1997, 137: 175-193

72 Hart S R. A large-scale isotope anomaly in the Southern Hemisphere mantle. Nature, 1984, 309: 753-757

73 Chen C H, Lee C Y, Shinjo R. Was there Jurassic paleo-Pacific subduction in South China?: Constraints from ${ }^{40}$ Ar $/{ }^{39}$ Ar dating, elemental and $\mathrm{Sr}-\mathrm{Nd}-\mathrm{Pb}$ isotopic geochemistry of the Mesozoic basalts. Lithos, 2008, 106: 83-92 
74 Wang Y J, Fan W M, Cawood P A, et al. Sr-Nd-Pb isotopic constraints on multiple mantle domains for Mesozoic mafic rocks beneath the South China Block hinterland. Lithos, 2008, 106: 397-308

75 Tapponnier P, Peltzer G, Armijo R, et al. Propagating extrusion tectonics in Asia: New nsights from simple experiments with plasticine. Geology, 1982, 10: 611-616

76 Chung S L, Lee T Y, Lo C H, et al. Intraplate extension prior to continental extrusion along the Ailao Shan Red River shear zone. Geo$\log$, 1997, 25: 311-314

77 Clift P, Lin J, Barkhausen U. Evidence of low flexural rigidity and low viscosity lower continental crust during continental break-up in the South China Sea. Mar Petrol Geol, 2002, 19: 951-970

78 Zhao D. Seismic images under 60 hotspots: Search for mantle plumes. Gondwana Res, 2007, 12: 335-355

79 Wang X C. Temperature, pressure, and composition of the mantle source region for late Cenozoic basalts in Hainan Island, Southeastern Asia: Results of a young thermal mantle plume close to subduction zones? J Petrol, 2011, doi:10.1093/petrology/egr061

80 Ho K S, Chen J C, Juang W S. Geochronology and geochemistry of late Cenozoic basalts from the Leiqiong area, southern China. J Asian Earth Sci, 2000, 18: 307-324

81 Zou H B, Fan Q C. U-Th isotopes in Hainan basalts: Implications for sub-asthenospheric origin of EM2 mantle endmember and the dynamics of melting beneath Hainan Island. Lithos, 2010, 116: 145-152

82 Lin J L, Fuller M, Zhang W Y. Preliminary Phanerozoic polar wander paths for the North and South China blocks. Nature, 1985, 313: 444-449

83 Ridd M F. South-east Asia as a part of Gondwanaland. Nature, 1971, 234: 531-533

84 Xu X S, O'Reilly S Y, Griffin W L, et al. Enrichment of upper mantle peridotite: Petrological, trace element and isotopic evidence in xenoliths from SE China. Chem Geol, 2003, 198: 163-188

85 Wu H H, Tsai Y B, Lee T Y, et al. 3-D shear wave velocity structure of the crust and upper mantle in South China Sea and its surrounding regions by surface wave dispersion analysis. Mar Geophys Res, 2004, 25: 5-27

86 Hofmann A W. Chemical differentiation of the Earth: The relationship between mantle, continental crust, and the oceanic crust. Earth Planet Sci Lett, 1988, 90: 297-314

87 White W M, Dupre B. Sediment subduction and magma genesis in the Lesser Antilles: Isotopic and trace element constraints. J Geophys Res, 1986, 91: 5927-5941

88 Mukasa S B, McCabe R, Gill J B. Pb isotopic compositions of volcanic rocks in the west and east Philippines arcs: Presence of the Dupal isotopic anomaly. Earth Planet Sci Lett, 1987, 84: 153-164

89 Zhang M, Tu K, Xie G, et al. Subduction-modified subcontinental mantle in south China: Trace element and isotope evidence in basalts from Hainan Island. Chin J Geochem, 1996, 15: 1-19

90 Sims K W W, DePaolo D J, Murrell M T, et al. Porosity of the melting zone and variations in the solid mantle upwelling rate beneath Hawaii: Inferences from ${ }^{238} \mathrm{U}_{-}{ }^{230} \mathrm{Th}^{-226} \mathrm{Ra}$ and ${ }^{235} \mathrm{U}^{2}{ }^{231} \mathrm{~Pa}$ disequilibria. Geochim Cosmochim Acta, 1999, 63: 4119-4138

91 White W M, McKenzie D. Magmatism at rift zone: The generation of volcanic continental margins and flood basalts. J Geophys Res, 1989, 94: 7685-7729

92 Menzies M A, Klemperer S L, Ebinger C J, et al. Characteristics of volcanic rifted margins. In: Menzies M A, Klemperer S L, Ebinger C J, et al, eds. Volcanic Rifted Margins: Boulder, Colorador. Geological Society of America Special Paper, 2002, 363: 1-14

93 Parsons B, Sclater J G. Analysis of variation of ocean-floor bathymetry and heat-flow with age. J Geophys Res, 1977, 82: 803-827

94 Morgan J P, Smith W H F. Flattening of the sea-floor depth age curve as a response to asthenospheric flow. Nature, 1992, 359: 524-527

95 Stein C A, Stein S. A model for the global variation in oceanic depth and heat-flow with lithospheric age. Nature, 1992, 359: 123-129

96 Kawakatsu H, Kumar P, Takei Y, et al. Seismic evidence for sharp lithosphere-asthenosphere boundaries of oceanic plates. Science, 2009, 324: 499-502

97 Kumar P, Kawakatsu H. Imaging the seismic lithosphere-asthenosphere boundary of the oceanic plate. Geochem Geophys Geosyst, 2011, 12: Q01006

98 Sobolev A V, Danyushevsky L V. Petrology and geochemistry of boninites from the north termination of the Tonga trench-Constraints on the generation conditions of primary high-Ca boninite magmas. J Petrol, 1994, 35: 1183-1211

99 Sobolev A V, Hofmann A W, Nikogosian I K. Recycled oceanic crust observed in "ghost plagioclase" within the source of Mauna Loa lavas. Nature, 2000, 404: 986-990

100 Hauri E. SIMS analysis of volatiles in silicate glasses, 2: Isotopes and abundances in Hawaiian melt inclusions. Chem Geol, 2002, 183: $115-141$ 